\title{
Cloud Robotics Law and Regulation ${ }^{+}$
}

\author{
Challenges in the Governance of Complex and Dynamic \\ Cyber-Physical Ecosystems
}

Eduard Fosch-Villaronga* and Christopher Millard**

\begin{abstract}
This paper assesses some of the key legal and regulatory questions arising from the integration of physical robotic systems with cloud-based services, also called "cloud robotics." The literature on legal and ethical issues in robotics has a strong focus on the robot itself, but largely ignores any background information processing. Conversely, the literature on cloud computing rarely addresses human-machine interactions, which raise distinctive ethical and legal concerns. In this paper we investigate, from legal and regulatory perspectives, the growing interdependence and interactions of tangible and virtual elements in cloud robotics environments. We highlight specific problems and challenges in regulating such complex and dynamic ecosystems, and explore potential solutions. To illustrate practical challenges, we consider several examples of cloud robotics ecosystems involving multiple parties, various physical devices, and various cloud services. These examples illuminate the complexity of interactions between relevant parties. By identifying pressing legal and regulatory issues in relation to cloud robotics we hope to inform the policy debate and set the scene for further research.
\end{abstract}

\section{Keywords}

cloud, cloud computing, cloud robotics, robots, cyber-physical system, law, technology, policy, human-robot interaction, privacy, data protection, product safety.

JEL Classification: K12, K13, K20, K23, K24, K33, K39, K42, L50, 025, 030, 031, 032, 033, 038.

\footnotetext{
+ This paper has been produced by members of the Cloud Legal Project, Centre for Commercial Law Studies, Queen Mary University of London. The authors are grateful to members of the Microsoft Cloud Computing Research Centre for helpful comments and to Microsoft for the generous financial support that has made this research possible. Responsibility for views expressed, however, remains with the authors.

* Researcher, Cloud Legal Project and Microsoft Cloud Computing Research Centre, both at the Centre for Commercial Law Studies, Queen Mary University of London

** Professor of Privacy and Information Law and Project Leader, Cloud Legal Project, Centre for Commercial Law Studies, Queen Mary University of London. Joint Director of the Microsoft Cloud Computing Research Centre.
} 


\section{Table of Contents}

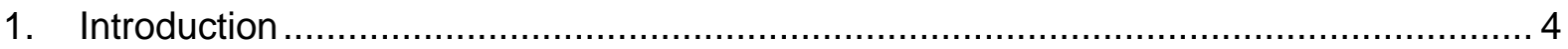

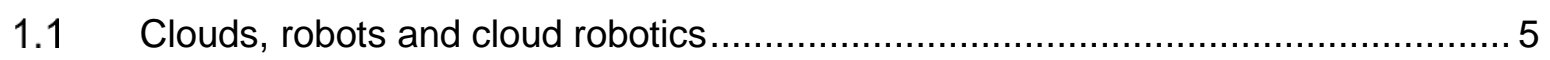

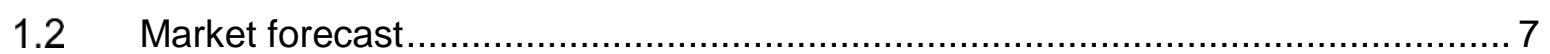

1.3 Legal and regulatory considerations in cloud robotics ..................................... 7

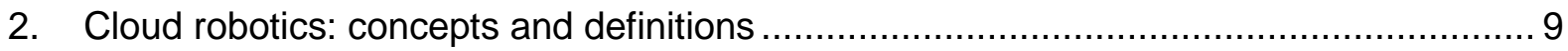

$2.1 \quad$ The tangible aspect of cloud robotics: the robot.............................................. 9

2.2 The intangible aspect of cloud robotics: cloud services..................................... 13

2.3 Cloud robotics: the synthesis of robots and cloud services ............................. 15

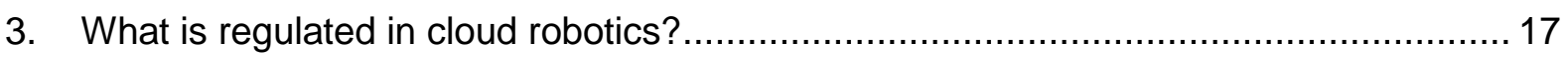

3.1 The fragmented and uncertain regulatory framework for cloud robotics .............. 17

3.2 A balance is needed between private standard-setting and public law-making in regulating cloud robotics.................................................................................. 20

3.2.1 Why standards are good for cloud computing and robotics ........................... 20

3.2.2 Factors complicating the development of standards for cloud robotics.............. 22

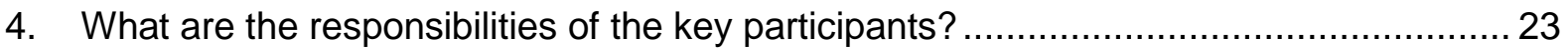

4.1 Attributing legal responsibility in complex multi-party ecosystems...................... 23

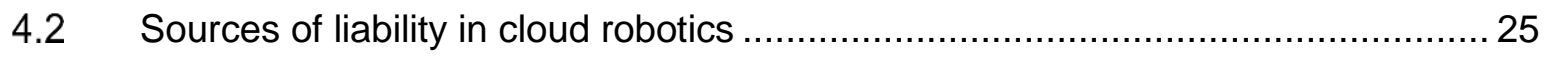

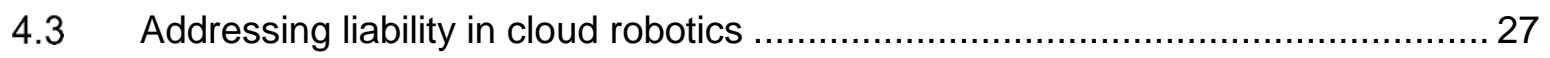

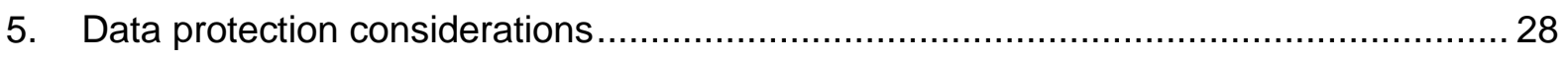

5.1 In a cloud robotics ecosystem, it may be difficult to identify the controllers and

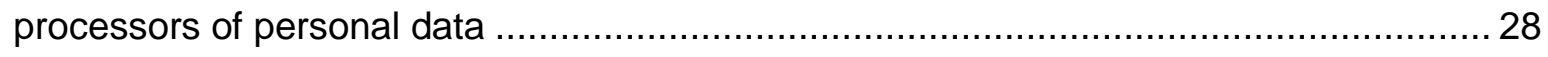

5.2 Ensuring transparency in cloud robotics may be challenging ........................... 29

5.3 It is unclear how data portability will work in cloud robotics .............................. 30

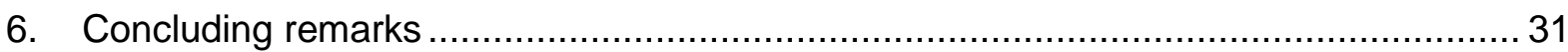

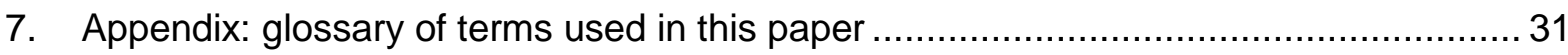




\section{Introduction}

The insertion of cyber-physical systems (CPSs) in society is accelerating. CPSs integrate computational and physical capabilities, as well as network and communication processes, in order to interact with their surroundings. ${ }^{1}$ CPSs typically involve networked computers, robots, artificial intelligence technologies, ${ }^{2}$ and things ${ }^{3}$ that increasingly interact with humans in private, professional or public settings. Examples include self-driving cars, healthcare robots, smart home appliances, drones, wearables, robotic toys, and industrial robots. CPSs can enhance physical and cognitive capabilities of elderly, ill and disabled people, ${ }^{4}$ optimize air quality monitoring, ${ }^{5}$ speed the boarding process at airports, ${ }^{6}$ or even become intimate companions for humans. ${ }^{7}$ In industrial environments, CPSs monitor physical processes in factories and make decentralized decisions while communicating with each other. ${ }^{8}$ Just as the Internet changed the way people interacted with each other and with information, some argue that CPSs will change the way humans interact with and control the physical world. ${ }^{9}$

The common characteristic of these systems is that they create an interconnected structure where the virtual and the physical intersect. They enable communication between the virtual and the physical through sensor networks and cloud platforms, or between different objects, typically via an Internet of Things (IOT) structure. The basic component framework of a CPS ecosystem will typically include: cloud platforms, embedded systems and networks of

\footnotetext{
1 Baheti, R., and Gill, H. "Cyber-physical systems." The impact of control technology 12, no. 1 (2011): 161-166.

2 "Ethical Aspects of Cyber-Physical Systems Scientific Foresight study," European Parliamentary Research Service, Scientific Foresight Unit (STOA), last modified June 2016, http://www.europarl.europa.eu/RegData/etudes/STUD/2016/563501/EPRS STU\%282016\%2956350 1 EN.pdf

${ }^{3}$ Hon, W. K., Millard, C. and Singh, J. "Twenty Legal Considerations for Clouds of Things." Queen Mary School of Law Legal Studies Research Paper No. 216/2016. (2016). Available at SSRN: https://ssrn.com/abstract=2716966.
}

4 Tapus, A., Fasola, J., and Mataric, M.J. "Socially assistive robots for individuals suffering from dementia." In Human-Robot Interaction Intl. Conf., Workshop on Robotic Helpers: User Interaction, Interfaces and Companions in Assistive and Therapy Robotics (2008).

5 In the CREATE Lab at Carnegie Mellon University a start-up called "Airviz Inc" has developed "speck", an air monitor system that provides users with information about air quality so that they can make an informed decision about how to improve their personal air quality. Cfr.: "Speck Sensor", Airviz Inc., Accessed April 10 2018, https://www.specksensor.com/

6 "British Airways transforms international boarding experience," Media Centre British Airways, Accessed April 12, 2018 http://mediacentre.britishairways.com/pressrelease/details/86/2017$\underline{228 / 9072}$

7 Danaher, J., and McArthur, N. eds. Robot sex: Social and ethical implications. MIT Press, 2017.

8 "What Everyone Must Know About Industry 4.0", Marr, B., Forbes, last modified June 20, 2016, https://www.forbes.com/sites/bernardmarr/2016/06/20/what-everyone-must-know-about-industry-40/\#236527ad795f See also Lasi, Heiner, Peter Fettke, Hans-Georg Kemper, Thomas Feld, and Michael Hoffmann. "Industry 4.0." Business \& Information Systems Engineering 6, no. 4 (2014): 239242.

${ }^{9}$ Lee, J. "Smart factory systems." Informatik-Spektrum 38, no. 3 (2015): 230-235. See also He, K., and Jin, M. "Cyber-Physical systems for maintenance in Industry 4.0." Master Thesis, Jönköping University, School of Engineering, JTH (2016). 
sensors. ${ }^{10}$ Of the various types of embedded systems, this paper focuses on robots. The term 'robot' can mean many things and we explore the boundaries of the concept in this paper. Our particular interest, however, is in actuated mechanisms that perform tasks for humans via ecosystems that integrate robots, embedded sensors, and cloud services. We will not consider robots that have no physical embodiment, such as chatbots.

\subsection{Clouds, robots and cloud robotics}

Cloud computing involves the use of computing resources over a network, typically the Internet, scalable according to demand. In addition to the well-established Infrastructure, Platform, and Software as a Service (laaS, PaaS, and SaaS) service models, cloud providers also provide specialist cloud services such as Machine Learning as a Service (MLaaS) and Blockchain as a Service (BaaS). ${ }^{11}$ Although the concept of "Robot/Robotics as a Service (RaaS)" exists, it is ambiguous. In some cases, it can refer to a business model whereby robotic systems are rented for a period of time, normally with technical support, real-time monitoring, and other services. ${ }^{12}$ In other cases, it can refer to the use of a serviceoriented architecture (SOA) for robotics, also called "cloud robotics." ${ }^{13}$ In this paper we will refer to cloud robotics as cloud services providing computation, data and / or storage to support the operation of a robot. ${ }^{14}$

Cloud services can help robots mitigate the limitations of their embodiment, typically battery life, weight, storage limitations or the inability to process all the information collected by their sensors in real-time. Moreover, cloud computing enables smarter robots, allowing the robot to offload heavy computational tasks such as navigation, speech or object recognition. ${ }^{15}$ Current applications of cloud robotics include robots for sustainable agriculture; ${ }^{16}$ for industry

10 Yen, C.T., Liu, Y.C., Lin, C.C., Kao, C.C., Wang, W.B. and Hsu, Y.R. "Advanced manufacturing solution to industry 4.0 trend through sensing network and Cloud Computing technologies." In 2014 IEEE International Conference on Automation Science and Engineering (CASE), IEEE, (2014): pp. 1150-1152.

11 Singh, J., and Michels, J. D., "Blockchain As a Service: Providers and Trust" Queen Mary School of Law Legal Studies Research Paper No. 269/2017 (2017). Available at SSRN: https://ssrn.com/abstract=3091223.

12 "Robots in the cloud: How robotics-as-a-service can help your business," Violino, B. ZDNet, last modified May 1, 2017, https://www.zdnet.com/article/robots-in-the-cloud/.

${ }^{13}$ We will explore these differences further in the sections that follow. For now, see Chen, Yinong, Zhihui Du, and Marcos García-Acosta. "Robot as a service in cloud computing." In 2010 Fifth IEEE International Symposium on Service Oriented System Engineering (SOSE), IEEE, (2010): 151-158.

${ }^{14}$ For a similar approach, see Kehoe, B., Sachin P., Abbeel, P., and Goldberg, K.. "A survey of research on cloud robotics and automation." IEEE Trans. Automation Science and Engineering 12, no. 2 (2015): 398-409, who described cloud robotics as "any robot (...) that relies on data or code from a network to support its operation, i.e. where not all sensing, computation and memory is integrated into a single standalone system," although this definition has an overfocus on the robot rather than the service.

15 "Cloud Robotics," Kohler, D. et al., Google, I/O, 2011, Accessed April 12, 2018, https://www.youtube.com/watch?v=FxXBUp-4800

${ }^{16}$ For example, VINBOT, an autonomous vineyard robot designed to optimise yield management and grape quality, has a small onboard computer that offloads data-intensive computer vision algorithms to be processed in a cloud. "VINBOT Report Summary," CORDIS, Accessed October 11, 2018, https://cordis.europa.eu/result/rcn/213942 en.html. See also "VINBOT: Autonomous Cloud Computing Vineyard Robot to Optimize Yield Management and Wine Quality" ICT Agri Era-Net, Accessed April 10, 2018, http://ict-agri.eu/node/36570. 
and manufacturing; ${ }^{17}$ or for domestic purposes and elderly care. ${ }^{18}$ There are, however, constraints on what can be offloaded to a cloud. For example certain safety and security features may need to function locally on a device.

In this paper we focus on robots that are typically classified as industrial or service robots, based on whether these robots "perform useful tasks for humans" or whether they are used for "industrial automation applications."19 Among service robots, some are designed to interact with us socially, ${ }^{20}$ others physically. ${ }^{21}$ Social robots may express and perceive emotions, communicate through high-level dialogue, learn and recognize models of other agents, establish and/or maintain social relationships, and use natural cues such as gaze or gestures. ${ }^{22}$ Such robots have been deployed in therapy, education or entertainment in public spaces such as airports or shopping centres. Non-social robots include service robots that do not interact with humans socially.

The physical embodiment of a robot distinguishes it from mere virtual agents, and plays a major role in many applications. ${ }^{23}$ Nonetheless, its physical embodiment confines its capabilities. In this paper we focus on physically embodied robots and we exclude mere loT things as we are interested in robots that sense, think, act and move. ${ }^{24}$ Although it has been argued that robots do not think but rather process information and weight potential outcomes, ${ }^{25}$ the word "think" should not be interpreted narrowly. ${ }^{26}$ Robots may also move around their environment to perform intended tasks. ${ }^{27}$ This paper does not, however, cover self-driving cars or drones specifically. Transport robots and drones raise distinct concerns from industrial or service robots under road traffic laws or aviation regulations. Rather, we focus on robots that move but do not fly or move as fast as a car. ${ }^{28}$

\footnotetext{
17 Lasi, et al. (2014), supra note 8.

18 "Buddy. The Companion Robot" Retrieved from http://www.bluefrogrobotics.com/en/buddy/.

19 ISO 8373:2012 - Robots and robotic devices - Vocabulary.
}

20 Breazeal, C., and Scassellati, B. "How to build robots that make friends and influence people." In Proceedings 1999 IEEE/RSJ International Conference on Intelligent Robots and Systems. IROS'99. vol. 2, (1999): 858-863.

${ }^{21}$ For example, exoskeletons. See Zhijun, L., Huang, B., Zhifeng Y., Deng, M. and Yang, C. "Physical Human-Robot Interaction of a Robotic Exoskeleton By Admittance Control." IEEE Transactions on Industrial Electronics (2018): 9614-9624.

${ }^{22}$ Fong, T., Nourbakhsh, I., and Dautenhahn, K. "A survey of socially interactive robots." Robotics and autonomous systems 42, no. 3-4 (2003): 143-166.

${ }^{23}$ Ibidem. See also the definition of robot embodiment: "that which establishes a basis for structural coupling by creating the potential for mutual perturbation between system and environment," in Dautenhahn, K., Ogden, B., and Quick, T. "From embodied to socially embedded agents-implications for interaction-aware robots." Cognitive Systems Research 3, no. 3 (2002): 397-428.

24 We emphasize the word think because it goes beyond the definition of thing given by Hon, et al. (2016), supra note 3.

${ }^{25}$ Lutz, C., and Tamò, A. "RoboCode-Ethicists: Privacy-friendly robots, an ethical responsibility of engineers?" In Proceedings of the ACM Web Science Conference, ACM (2015): 21.

26 Turing, A.M. (1950). "Computing machinery and intelligence." Mind, 59, 236, (1950): 433-460.

27 See the definition of robot of ISO 8373:2012 Robots and Robotic Devices - Vocabulary. Please note that this standard is under revision and will be substituted by a new version.

${ }^{28}$ This is consistent with the approach taken in ISO 13482:2014 on Safety Requirements for Personal Care Robots which does not cover flying or underwater robots, or robots travelling faster than $20 \mathrm{~km} / \mathrm{h}$. 


\subsection{Market forecast}

The rate of deployment of industrial and service robots has increased substantially in recent years and continues to grow. According to the International Federation of Robotics (IFR), 212,000 industrial robot units were sold in 2016, and annual sales of 520,900 units are expected by $2020 .^{29}$ The IFR estimates that more than 1.7 million new industrial robots will be installed in factories around the world between 2017 and 2020. In 2016, the total number of service robots for personal and domestic use was about 6.7 million units. ${ }^{30}$ IFR projects the sales of all types of robots for domestic tasks, including robotic vacuums, lawn-mowing robots, and toy robots will reach 32.4 million units in the period 2018-2020.

A recent report forecasts that the cloud robotics market will grow between 2017 and 2022 at a compound annual growth rate of $28.1 \%$ boosting the market from USD 2.20 billion to USD 7.51 billion. ${ }^{31}$ The main cloud robotics vendors are located in North America, including Amazon Robotics, Google, IBM, Microsoft, CloudMinds, Hit Robotics Group, Tend, and C2RO. In the Asia Pacific (APAC) region, the market is led by companies such as Huawei (China), V3 Smart Technologies (Singapore), and Rapyuta Robotics (Japan). The British company Ortelio Ltd. is the only European company regarded as being among these worldleading players. $^{32}$

\subsection{Legal and regulatory considerations in cloud robotics}

The combination of cloud services with robots is not necessarily straightforward. Cloud computing encompasses various deployment models and may involve multiple service layers and (sub-)providers, with supply chains that are often opaque. ${ }^{33}$ Such complexity can

29 The report from 2018 (with data for 2017) is not yet available, and the numbers given are always from the previous year. See "Executive Summary World Robotics 2017 Industrial Robots" International Federation of Robotics, Accessed April 10, 2018, https://ifr.org/downloads/press/Executive Summary WR 2017 Industrial Robots.pdf

30 "Executive Summary World Robotics 2017 Service Robots" International Federation of Robotics, $\begin{array}{lll}\text { Accessed } & \text { April } & 10,\end{array}$ https://ifr.org/downloads/press/Executive Summary WR Service Robots 2017 1.pdf.

31 "Cloud Robotics Market by Component, Service Model, Application, Deployment Model, End-User And Region - Global Forecast to 2022" MarketsandMarkets, Accessed April 10, 2018, https://www.marketsandmarkets.com/PressReleases/cloud-robotics.asp. Please notice that these numbers may vary depending on the variables used. Previous reports, for instance, forecasted a compound annual growth rate of 32.4\% between 2016 and 2022, cfr. "Worldwide Cloud Robotics Market; By Types (Industrial, commercial, military, personal), Connectivity Technology (Bluetooth, WiFi, 3G, 4G, and 5G), Deployment Model (Public, Private, and Hybrid), End-users (Manufacturing, Aerospace and defence, Education, Logistics, Agriculture, Home and Construction), By Region Drivers, Opportunities, Trends, and Forecasts, 2016-2022," Infoholic Research, Accessed April 10, 2018, $\quad$ https://www.infoholicresearch.com/report/worldwide-cloud-robotics-market-driversopportunities-trends-and-forecasts-2016-2022/.

32 "The global cloud robotics market is expected to grow from USD 2.20 billion in 2017 to USD 7.51 billion by 2022, at a Compound Annual Growth Rate (CAGR) of $28.1 \%$ ", CISION, PR Newswire, last modified March 1, 2018, https://www.prnewswire.com/news-releases/the-global-cloud-roboticsmarket-is-expected-to-grow-from-usd-220-billion-in-2017-to-usd-751-billion-by-2022-at-a-compoundannual-growth-rate-cagr-of-281-300606841.html.

${ }^{33}$ Hon, W.K., and Millard, C. "Cloud Technologies and Services." In Millard, C. (ed) Cloud Computing Law. Oxford University Press, 2013, 3-17. 
give rise to significant challenges in relation to control, security, and risk management. ${ }^{34}$ As with loT ecosystems more generally, the use of cloud services in robotics environments may add further complications, including very diverse legal obligations and liabilities, such as fragmented contractual arrangements, uncertainties regarding software and data ownership and use rights, and complex privacy and data protection compliance requirements. ${ }^{35}$

Acknowledging the complex multidisciplinary, multi-layered and multi-level interplay involving clouds, robots and humans, the European Parliament (EP) has recently proposed various principles and requirements for a comprehensive regulatory framework. ${ }^{36}$ These include the concept of reversibility, the inclusion of a protective stop, and the possibility of ascribing the status of electronic persons to robots to make them responsible for any damage they may cause. Meanwhile, the EU's General Data Protection Regulation (GDPR) ${ }^{37}$ includes rules on automated decision-making processes, ${ }^{38}$ the right to be forgotten, ${ }^{39}$ and data protection by design, all of which are likely to have an impact on the development and deployment of cloud robotics ecosystems. ${ }^{40}$

The purpose of this paper is to clarify the main legal and regulatory issues that are likely to arise when robots are combined with cloud services. We analyse the suitability of the GDPR, the EP resolution, and other similar initiatives such as relevant industry standards, ${ }^{41}$ as regulatory models for robots. ${ }^{42}$ There is a dearth of specific research in this area. On the one hand, the extensive literature on legal and ethical issues in robotics has a strong, indeed

${ }^{34}$ Hon, W.K., and Millard, C. "Control, Security, and Risk in the Cloud." In Millard, C. (ed) Cloud Computing Law. Oxford University Press, 2013, 18-35.

35 Millard, C., Hon, W. K., and Singh, J. "Internet of Things Ecosystems: Unpacking Legal Relationships and Liabilities." In 2017 IEEE International Conference on Cloud Engineering (IC2E), (2017): 286-291.

36 Civil Law Rules on Robotics European Parliament resolution of 16 February 2017 with recommendations to the Commission on Civil Law Rules on Robotics (2015/2103(INL)).

37 Regulation (EU) 2016/679 of the European Parliament and of the Council of 27 April 2016 on the protection of natural persons with regard to the processing of personal data and on the free movement of such data, and repealing Directive 95/46/EC (General Data Protection Regulation).

38 Kamarinou, D., Millard, C., and Singh, J. "Machine Learning with Personal Data". In: Leenes, Ronald, Rosamunde Van Brakel, Serge Gutwirth, and Paul De Hert, eds. Data Protection and Privacy: The Age of Intelligent Machines. Bloomsbury Publishing, (2017): 89-114.

39 Fosch-Villaronga, E., Kieseberg, P., and Li, T. "Humans forget, machines remember: Artificial intelligence and the right to be forgotten." Computer Law \& Security Review, 34(2), (2018): 304-313.

${ }^{40}$ Leenes, R., and .Lucivero, F. "Laws on robots, laws by robots, laws in robots: regulating robot behaviour by design." Law, Innovation and Technology 6, no. 2 (2014): 193-220.

${ }^{41}$ British Standard (BS) 8611:2016 Guide to the ethical design and application of robots and robotic systems, and the IEEE SA 7000 series concerning the ethics of autonomous and intelligent systems

42 These include "AI Now Institute Report" Campolo, A., Sanfilippo, M.; Whittaker, M., Crawford, K., AI Now Institute, last modified 2017, https://ainowinstitute.org/Al Now 2017 Report.pdf. See also "ELS issues in robotics and steps to consider them. Part 2: Robotics and Regulations," Bottalico, B. Santosuosso, A., Goodenough, O., de Bruin, R., Holder, C., Gôme, C., ..., Leroux, C., last modified 2016, $\quad$ https://www.eu-robotics.net/cms/upload/downloads/Rockeu1/2016-0816 RockEU deliverable D3.4.1-part2.pdf; and "Guidelines on Regulating Robotics," Palmerini, E., Azzarri, F., Battaglia, F., Bertolini, A., Carnevale, A., Carpaneto, J., ..., Warwick, K, RoboLaw Regulating Emerging Robotic Technologies in Europe: Robotics facing Law and Ethics, last modified 2014,

http://www.robolaw.eu/RoboLaw files/documents/robolaw d6.2 guidelinesregulatingrobotics 201409 22.pdf. 
often exclusive, focus on the robot itself and largely ignores any background information processing. On the other hand, most of the literature covering cloud computing fails to address human-robot interactions, which raise distinctive ethical and legal concerns. Hence, this paper contributes to the literature by investigating, from legal and regulatory perspectives, the growing interdependence and interactions of tangible and virtual elements in cloud robotics. We highlight specific problems and challenges in regulating complex and dynamic cyber-physical ecosystems, and explore potential solutions.

Following this introduction, section 2 of this paper sets the scene by introducing the concepts of robot, cloud, and cloud robotics. Section 3 draws attention to regulatory challenges, and identifies various uncertainties in the current legal framework applicable to cloud robotics. After noting that a balance between private rule-making and public policy-making is needed, section 4 tackles responsibility aspects, focusing mainly on the attribution of responsibility and liability in complex cloud robotics ecosystems. We consider the controversial concept of 'personhood' for robot technology, identify different sources of liability for robots using cloud services, and propose different ways to address related problems. Data protection considerations are identified in section 5, including challenges in identifying relevant controllers and processors of personal data, as well as how data protection principles apply in cloud robotics environments. The paper closes with some conclusions in section 6 .

\section{Cloud robotics: concepts and definitions}

The idea of cloud robotics began to emerge more than two decades ago. In 1997 Ibana proposed the creation of remote-brained robots as a solution to the dependence that robots generally have on heavy on-board processing when interacting with the real world. According to Ibana, a robot could be designed with a large-scale, remote, powerful brain and a lightweight body. ${ }^{43}$ The body provides an interface for a brain in the external world; the brain provides a program that receives sensor information from the robot and sends actuation commands to the body. To Ibana, the body, the brain, and the channel of communication between these two constituted the remote-brained robot ecosystem. ${ }^{44}$

\subsection{The tangible aspect of cloud robotics: the robot}

The definition of robot is highly contested: it seems that everyone knows what a robot is, until asked to give a definition. ${ }^{45}$ This section provides a working definition for the word 'robot,' and a description of the parts that typically constitute a robot. We also review discussions on whether a definition for robots is needed or not.

\footnotetext{
${ }^{43}$ As Ibana puts it, "a remote-brained robot does not bring its own brain with the body. It leaves the brain in the mother environment, by which we mean the environment in which the brain's software is developed, and talks with it by wireless links." See lbana, M. "Remote-brained Robots." In Pollack, M. E. Proceedings of the 15th International Joint Conference on Artificial Intelligence (IJCAI-97), (1997): 1593-1606.

44 Ibid.

45 The original aphorism related to the definition of emotions: "everyone knows what an emotion is, until asked to give a definition." See Fehr, B., and Russell, J.A. "Concept of emotion viewed from a prototype perspective." Journal of experimental psychology: General 113, no. 3 (1984): 464. Regarding the lack of a consistent and accepted definition of robotics across different stakeholders, see Robotics 2020 Multi-Annual Roadmap For Robotics in Europe. Call 2 ICT 24 Horizon 2020, SPARC, 2015, p. 287. See also "What is a robot," Matt Simon, Wired, last modified August 27, 2017, https://www.wired.com/story/what-is-a-robot/.
} 
For the purpose of this paper, a robot is a movable machine that performs tasks either automatically or with a degree of autonomy: ${ }^{46}$

- movable because it has the capacity for movement, within its environment or on its own;

- $\quad$ machine because it is an apparatus using mechanical power;

- that performs tasks;

- either automatically or with a degree of autonomy because it works by itself with or without human control.

The body of a robot will normally be an articulated structure with links that are interconnected by joints. Actuators are incorporated into these joints to enable movement. Because acting is the capability to physically interact with the environment, a robot will typically include multiple sensors to control the internal state of the robot (called proprioceptors) and to measure environmental parameters (exteroceptors). ${ }^{47}$ Proprioceptors are sensors that measure the position and movement of the robot. Exteroceptors are sensors that receive external stimuli, and can be of a wide range of types: light, sound, temperature, contact, proximity, pressure, acceleration, etc. ${ }^{48}$ The following image is an example of a robot and its sensors:

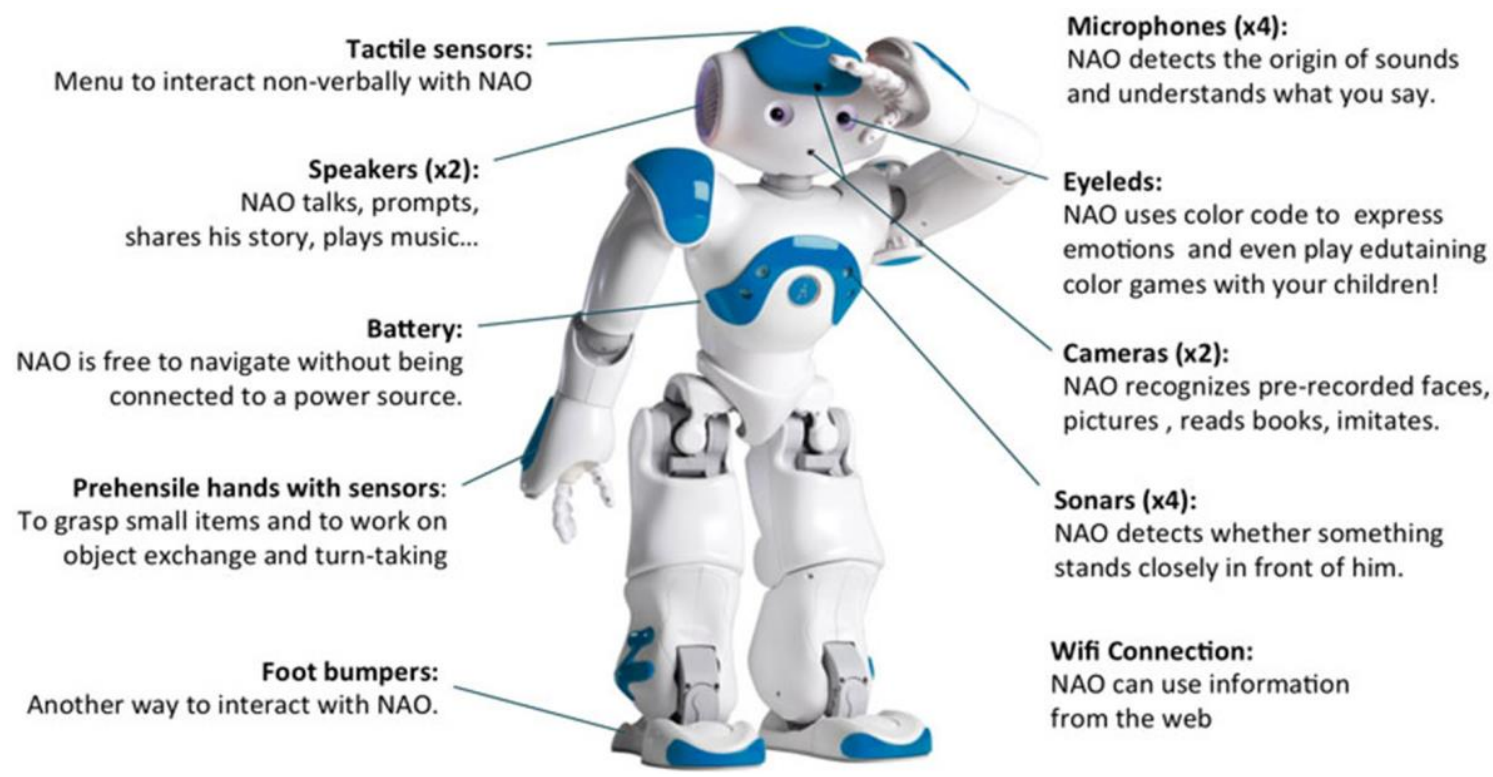

Figure 1: Sensors incorporated in the NAO robot from Softbank ${ }^{49}$

${ }^{46}$ See ISO ISO 8373:2012(en) Robots and robotic devices - Vocabulary, entry 2.6 "robot: actuated mechanism programmable in two or more axes with a degree of autonomy, moving within its environment, to perform intended tasks. Autonomy is defined by ISO as: ability to perform intended tasks based on current state and sensing, without human intervention. See also the definition of Richards, N.M., and Smart, W.D. "How should the law think about robots?" (2016). In: Calo, R., Froomkin, A.M., and Kerr, I. eds. Robot law. Edward Elgar Publishing, 2016, 3-22: "a robot is a constructed system that displays both physical and mental agency but is not alive in the biological sense."

47 "Robot Sensors," University of Ottaay, last accessed July 31, 2018, http://www.site.uottawa.ca/ petriu/ELG5161-RobotSensors.pdf.

48 "Types of robot sensors," Robot Platform, last accessed July 31, 2018, http://www.robotplatform.com/knowledge/sensors/types of robot sensors.html.

49 "Features of NAO Robot," Gigabotics, Robotics Development and Research, last modified September 19, 2015, http://gigabotics.com/robotics/features-of-nao-robot/. 
The embodiment of the robot plays a crucial role in many applications: children feel stronger friendship bonds with a physical robot compared to a virtual avatar, ${ }^{50}$ the use of physicallypresent robot tutors produces better learning results, ${ }^{51}$ and individuals with cognitive impairments find the interaction more "efficient, natural, and preferred" with a physical robot than with a simulated one. ${ }^{52}$ Robot embodiment enhances presence, helps with the allocation of social-interactional intelligence typically via gaze and facial expressions, and makes robot task capabilities intelligible from the user perspective. ${ }^{53}$ This may enhance transparency of robot intentions and actions, and promote trust. Typical embodiments include anthropomorphic, zoomorphic, ${ }^{54}$ caricatured, and functional. ${ }^{55}$

Etymologically, the word robot derives from the archaic Czech word robota, and means "forced, serf labour." The word robot was introduced into the English vocabulary via the play "Rossumovi Univerzální Roboti" (Rossum's Universal Robots, R.U.R.), written by Karek Čapek in 1920, and staged in New York in $1922 .{ }^{56}$ Roboti were human-like machines that were supposed to do the tedious work of humans. With his play, Čapek wanted to criticize the mechanization of human workers as a result of the industrial revolution. ${ }^{57}$ Today, the Oxford dictionary defines a robot as "a machine resembling a human being and able to replicate certain human movements and functions automatically." 58

The legal and ethical communities have no generally accepted definition for the term robot. Some authors use definitions that include concepts related to 'intelligence' such as "machines, situated in the world, that sense, think and act." 59 Others, like the International

50 Sinoo, C., van der Pal, S., Olivier A., Henkemans, B., Keizer, A., Bierman, B., Looije, R., and Neerincx, M.A. "Friendship with a robot: Children's perception of similarity between a robot's physical and virtual embodiment that supports diabetes self-management." Patient education and counseling (2018): 1248-1255.

51 Leyzberg, D., Spaulding, S., Toneva, M., and Scassellati, B. "The physical presence of a robot tutor increases cognitive learning gains." In Proceedings of the Annual Meeting of the Cognitive Science Society, vol. 34, no. 34. 2012; see also Jung, Y., and Lee, K.M. "Effects of physical embodiment on social presence of social robots." Proceedings of PRESENCE (2004): 80-87.

52 Tapus, A., Tapus, C. and Mataric, M. "The role of physical embodiment of a therapist robot for individuals with cognitive impairments." In The 18th IEEE International Symposium on Robot and Human Interactive Communication, RO-MAN (2009): 103-107.

53 Shamekhi, A., Liao, Q.V., Wang, D., Bellamy, R.K., and Erickson, T. "Face Value? Exploring the Effects of Embodiment for a Group Facilitation Agent." CHI 2018, April 21-26, 2018, Montreal, QC, Canada.

54 Zoomorphic robots typically refer to pet-like robots such as Sony's toy dog - AIBO, but also to other types of animals such as dinosaurs - PLEO (see http://www.pleoworld.com/pleo rb/eng/index.php) or seals - PARO (see http://www.parorobots.com/). The latter is often used in therapeutic contexts to avoid personal traumas arising from pet therapies, as almost nobody knows how a seal behaves.

55 Such robots are normally designed according to their operational goals, and include industrial and service-oriented robots, see Fong et al. (2003), supra note 22.

56 Čapek, K. “RUR (Rossum's universal robots).” Penguin, 2014.

57 Horáková, J., and Kelemen, J. “Čapek, Turing, von Neumann, and the 20th century evolution of the concept of machine." In Proc. Intern. Conf. in Memoriam John von Neumann (2003): 121-135.

58 In the dictionary entry it is noted that this definition is found "especially in science fiction", see https://en.oxforddictionaries.com/definition/robot.

59 Bekey refers to "situated in the world" in order to distinguish a physical robot from a program running on a computer (software bot), see Bekey, G.A. "Current trends in robotics: technology and ethics." In Lin, P., Abney, K. and Bekey, G.A. (eds.) Robot ethics: the ethical and social implications of 
Organization for Standardization (ISO), define robot in more passive terms as "actuated mechanism(s) programmable in two or more axes with a degree of autonomy, moving within its environment, to perform intended tasks." ${ }^{00}$ Some legal scholars in the United States have defined a robot as a "constructed system that displays both physical and mental agency but is not alive in the biological sense." ${ }^{11}$ The Japanese Electric Machinery Law (1971) defined industrial robot as an "all-purpose machine, equipped with a memory device and a terminal device (end-effector), capable of rotation and of replacing human labour by the automatic performance of movements." 62

For the law to regulate something specifically it is not always necessary for that thing to be defined. For instance, the Directive that regulates electricity has not defined the term as such. ${ }^{63}$ Whether or not a definition is required may depend on the level of uncertainty surrounding a concept. For example, in a particular legislative context, would a definition of the word robot increase or reduce certainty as to the scope of the law?

The European Parliament favours the introduction of various definitions in this field and has called on the European Commission to define "cyber-physical systems," "autonomous systems," and "smart autonomous robots." In its resolution, the EP suggests taking into consideration the following characteristics: ${ }^{64}$

1. the acquisition of autonomy through sensors and/or by exchanging data with its environment (inter-connectivity) and the trading and analysing of those data;

2. self-learning from experience and by interaction (optional criterion);

3. at least a minor physical support;

4. the adaptation of its behaviour and actions to the environment;

5. and absence of life in the biological sense. ${ }^{65}$

In response, the EC acknowledged the need to update and complement the existing EU legal framework in order to cover areas such as automated vehicles or machines, additive manufacturing, collaborative robots/systems, or robots outside the industrial environment, as European standards do not currently cover those areas. ${ }^{66}$ However, the EC stated that it was

robotics. The MIT Press, 2012: 17-34. In a similar sense, see Calo, Ryan. "Robotics and the Lessons of Cyberlaw." Cal. L. Rev. 103 (2015): 513.

60 ISO 8373:2012 Robots and Robotic Devices - Vocabulary defines terms used in relation with robots and robotic devices operating in both industrial and non-industrial environments.

${ }^{61}$ Richards, and Smart (2016), supra note 46.

62 Extracted from Mathia, K. "Robotics for electronics manufacturing: principles and applications in cleanroom automation." Cambridge University Press, (2008): 8.

${ }^{63}$ Directive 2009/72/EC of the European Parliament and of the Council of 13 July 2009 concerning common rules for the internal market in electricity.

${ }^{64}$ In another part of the proposal the EP also called on the EC to propose "common Union definitions of cyber physical systems, autonomous systems, smart autonomous robots and their subcategories." (Emphasis added). See European Parliament Resolution (2017), supra note 36.

65 This list of characteristics illustrates how difficult it is to contain the scope of the concept of a robot as, arguably, they are characteristics of any smart device.

66 Spiliopoulou-Kaparia, M. "The evaluation of Directive 85/374/EEC on liability for defective products and Directive 2006/42/EC on machinery." European Stakeholder Forum - Workshop on Regulatory challenges for a digitizing industry Essen (February 2017). See also Simmonds, P., Brown, N., and Rentel, M. "Evaluation of Directive 2006/42/EC on Machinery. Final Report." Technopolis Group (2017); and the European Parliament Resolution (2017), supra note 36. 
not sure whether a definition of robot for regulatory purposes was needed. ${ }^{67}$ In a communication in April 2018, the EC set out a European Initiative on Al aimed at boosting the EU's technological and industrial capacity, preparing for socio-economic changes, and ensuring an appropriate ethical and legal framework. ${ }^{68}$ In it, there is no trace of the earlier discussions from 2017 on whether a definition of robots will be deemed necessary or not. We anticipate, however, that if robot technology is to be regulated explicitly, then a definition of robot is likely to be deemed necessary by legislators. ${ }^{69}$

\subsection{The intangible aspect of cloud robotics: cloud services}

The National Institute of Standards and Technology (NIST) has defined cloud computing as a "model for enabling ubiquitous, convenient, on-demand network access to a shared pool of configurable computing resources [...] that can be rapidly provisioned and released with minimal management effort or service provider interaction."70 lbana anticipated the development of service-oriented architectures (SOA) to support physical devices. A SOA is a software system within which services communicate with each other through standard interfaces. ${ }^{71}$ By including development platforms, execution infrastructure, and storage, cloud computing extends SOA further.

The availability of cloud resources can greatly enhance a robot's ability to perceive an environment, analyse how to execute an entrusted task, share that information with humans

67 "Follow up to the European Parliament resolution of 16 February 2017 on civil law rules on robotics (2015/2103(INL)" European Commission, Last modified May 16 2017, Available at http://www.eunited.net/robotics/news-events/robotics-news/european-commissions-response-to-the-europeanparliaments-resolution-on-civil-law-rules-on-robotics.html.

68 European Commission COM(2018) 237 final Communication From The Commission To The European Parliament, The European Council, The Council, The European Economic And Social Committee And The Committee Of The Regions on Artificial Intelligence for Europe

${ }^{69}$ We also considered, but found unconvincing, a lengthy definition produced in the context of the EU Robolaw project. This project aimed at providing guidelines on the regulation of robot technology. Although the project itself did not define what a robot is, two of the lead researchers, Bertolini and Palmerini, published an article that included this definition: "a machine, which (i) may be either provided of a physical body, allowing it to interact with the external world, or rather have an intangible nature - such as a software or program -, (ii) which in its functioning is alternatively directly controlled or simply supervised by a human being, or may even act autonomously in order to (iii) perform tasks, which present different degrees of complexity (repetitive or not) and may entail the adoption of not predetermined choices among possible alternatives, yet aimed at attaining a result or provide information for further judgment, as so determined by its user, creator or programmer, (iv) including but not limited to the modification of the external environment, and which in so doing may (v) interact and cooperate with humans in various forms and degrees." This definition is unlikely to be of much use for legal and regulatory purposes as it contains so many optional and alternative criteria. For more on this project, see "Regulating Robotics: A Challenge for Europe," Bertolini, A., and Palmerini, E. European Union, last modified 2014, www.europarl.europa.eu/RegData/etudes/IDAN/2014/509987/IPOL IDA(2014)509987(ANN01) EN.p df.

70 See Mell, P., and Grance, T. "The NIST Definition of Cloud Computing" Special Publication (2011): 2; and Kuan Hon and Millard (2013), supra note 33.

71 Shaw, M., and Garlan, D. "Software architecture." Vol. 101. Englewood Cliffs: Prentice Hall, (1996): 1-12; see also Thramboulidis, K.C., Doukas, G., and Koumoutsos,G. "A SOA-based embedded systems development environment for industrial automation." EURASIP Journal on Embedded Systems 2008, no. 1 (2007): 312671. 
or other robots, and react to the environment more efficiently. ${ }^{72}$ For example, the improved version of what used to be Google Goggles, ${ }^{73}$ Google Lens, ${ }^{74}$ or the Computer Vision API from Microsoft Azure, ${ }^{75}$ are visual analysis systems that enable a picture to be sent to a cloud service for comparison with a vast database of images to check for potential matches. Useful information in relation to the objects and people in the picture and their context can then be provided, in almost real time. ${ }^{76}$ Such image recognition services, together with the provision of contextual information and recommendations to take certain actions can be very useful to help robots avoid obstacles, recognize familiar objects or people, identify and describe new and unknown objects or people, or to understand how best to interact with an object or person.

In addition, having access to cloud-based map and navigation systems can help robots to navigate without relying on map building and planning. This can also allow robots to know where other humans or other robots are. Google offers cloud-based map and navigation services, ${ }^{77}$ including a turn-by-turn navigation system that helps users know where they are, where are they going, and how to get there. Other location-cloud companies, such as Here, provide accurate data regarding road geometry - height, slope, and curvature. ${ }^{78}$

Further, speech recognition powered by deep learning neural networks can be used to achieve a more natural human-robot interaction (HRI). ${ }^{79}$ Although unable to carry out general conversations, Google Duplex enables users to perform tasks over the phone in closed domains in the real world. ${ }^{80}$ Among some of the benefits, this technology could address accessibility and language barriers, for instance, by enabling robot users to carry out particular tasks notwithstanding visual or auditory impairments, or the inability to speak a particular language. ${ }^{81}$

72 The sense-think-act paradigm developed in the eighties has been revised several times, see Siegel, M. "The sense-think-act paradigm revisited." In ROSE'03 1st International Workshop on Robotic Sensing, (2003): 5; Lutz and Tamò (2015), supra note 25.

${ }^{73}$ As announced in the Google I/O 2017 Conference, see https://events.google.com/io2017/.

74 "Use Google Lens to Interact with your Photos," Google, Retrieved from https://support.google.com/photos/answer/7539151?c0=GENIE.Platform\%3DAndroid\&hl=en.

75 "Computer Vision API," Microsoft Azure, Retrieved from https://azure.microsoft.com/en$\mathrm{gb} /$ services/cognitive-services/computer-vision/.

76 "From virtual assistant to Google lens here are key takeaways from I/O Conference," The Economic Times Online, Last modified May 18, 2017, https://economictimes.indiatimes.com/tech/software/keytakeaways-from-google/articleshow/58722738.cms.

77 "Google Maps," Google, Retrieved from: https://enterprise.google.com/maps/.

78 "HERE Map Data. Harnessing the power of location data," Here, Retrieved from https://www.here.com/en/products-services/map-content/here-map-data.

79 Van Den Oord, A., Dieleman, S., Zen, H., Simonyan, K., Vinyals, O., Graves, A., ... and Kavukcuoglu, K. "Wavenet: A generative model for raw audio." (2016) arXiv preprint arXiv:1609.03499.

80 "Google Duplex: An Al System for Accomplishing Real-World Tasks Over the Phone," Google Al Blog, Last modified May 8, 2018, https://ai.googleblog.com/2018/05/duplex-ai-system-for-naturalconversation.html.

$81 \mathrm{lbid}$. 


\subsection{Cloud robotics: the synthesis of robots and cloud services}

The practical synthesis of remote-computing services with embedded systems and robotic applications to allow machine-to-machine communication began in the early $2000 \mathrm{~s} .{ }^{82}$ In 2005, the Microsoft Robotics Developer Studio was launched, and a prototype of a SOA robot was implemented..$^{83}$ In the years that followed, researchers and developers saw the potential for integrating cloud computing services with robot technologies, and started calling this combination "cloud robotics." 84

The RoboEarth project (2010-2014) developed a "Cloud Robotics infrastructure, which includes everything needed to close the loop from robot to the cloud and back to the robot." 85 The catalyst for the project was the assumption that (at that time) near future robots would need to "reliably perform tasks beyond their explicitly pre-programmed behaviours and quickly adapt to the unstructured and variable nature of tasks;" 86 something unlikely without a cloud platform. The concept of cloud robotics has since been extended to cover robots that utilise sensing, computation and memory that are not integrated into their stand-alone systems. ${ }^{87}$

Cloud robotics, then, falls somewhere on a spectrum between an essentially physical robot and a purely virtual Al. There is considerable flexibility as to where specific functionality should be located on the spectrum. For instance, if a robot takes pictures and processes speech, there is a design decision to be made as regards where the pictures are stored and where the speech is processed. In theory, it could be anywhere on the spectrum, closer to the physicality or to the virtuality of cloud robotics. In practice, there is a trend to move an increasing proportion of the processing functionality to the cloud. However, technical factors, including network availability, latency (reaction time), or cybersecurity concerns about an increase in attack surfaces, may limit the use of cloud services for particular processes. For our purposes, cloud robotics must involve some elements of physicality and some elements of cloud computing.

Some robots have a high dependency on their physical components because they need to perform a task that affects the physical environment, for instance to pick up a glass of water or lift a patient. Other robots may have a greater reliance on the cloud, for instance, if a novel question needs to be answered in real-time and in natural language.

${ }^{82}$ Chen, Y., and Bai, X. "On robotics applications in service-oriented architecture." In CDCS'08. 28th International Conference on Distributed Computing Systems Workshops, (2008): 551-556.

83 Note that the Microsoft Robotics Developer Studio does not exist anymore, see more information at "Microsoft Shuts Down Its Robotics Group," Guizzo, E. IEEE Spectrum, last modified September 25, 2014, https://spectrum.iee.org/automaton/robotics/robotics-software/microsoft-shuts-down-itsrobotics-group. See also Chen et al. (2010), supra note 13.

84 Kuffner, J. "Cloud-Enabled Humanoid Robots. Humanoids2010 Workshop "What's Next". Google Research. The Robotics Institute, Carnegie Mellon University, 2010; see also Arumugam, R., Vikas R.E., Bingbing, L., Xiaojun, W., Baskaran, K., Kong, F.F., Kumar, A.S., Meng, K.D., and Kit, G.W. "DAvinCi: A cloud computing framework for service robots." In 2010 IEEE International Conference on Robotics and Automation (ICRA), (2010): 3084-3089; and Hu, G., Tay, W.P., and Wen, Y. "Cloud Robotics: Architecture, Challenges and Applications." IEEE Network, vol. 26, issue 3, (2012): 21-28.

85 "What is RoboEarth?", RoboEarth, last accessed September 10, 2018, http://roboearth.ethz.ch/.

86 Waibel, M., Beetz, M., Civera, J., d'Andrea, R., Elfring, J., Galvez-Lopez, ... and D., Haussermann K. "A world wide web for robots." IEEE Robotics \& Automation Magazine 18, no. 2 (2011): 69-82.

87 Kehoe, B., Patil, S., Abbeel, P., and Goldberg, K. "A survey of research on cloud robotics and automation." IEEE Trans. Automation Science and Engineering 12, no. 2 (2015): 398-409. 
To illustrate these relationships, consider Swiss startup Avatarion's project "Avatar Kids". ${ }^{88}$ Avatar Kids aims to help children and young adults who are staying in hospital long-term to keep in touch with friends and relatives. The company has a partnership with the company Softbank Robotics and uses Pepper and NAO robots as robotic avatars that link patients to their friends or families. ${ }^{89}$ In 2017 , the project included 25 robots and six hospitals. Initially, the project lacked telemetry data, i.e. an automated communication process to monitor data remotely, and the users could not interact remotely with the robots. This made it impossible for the company to gain an accurate and deep understanding of the use and functioning of the robots. ${ }^{90}$

Avatarion worked with Microsoft to develop a cloud-based solution. First, it used Azure loT Hub for telemetry data collection, asset management, and remote control. Second, it used Azure Stream Analytics to gain real-time insights and predictions from the data generated by the robots, such as location, hours of function, robot behaviour, and successful/failed interactions. Third, it used Azure SQL Database for cloud storage and Microsoft Power BI to create a dashboard for Avatarion and its customers. ${ }^{91}$

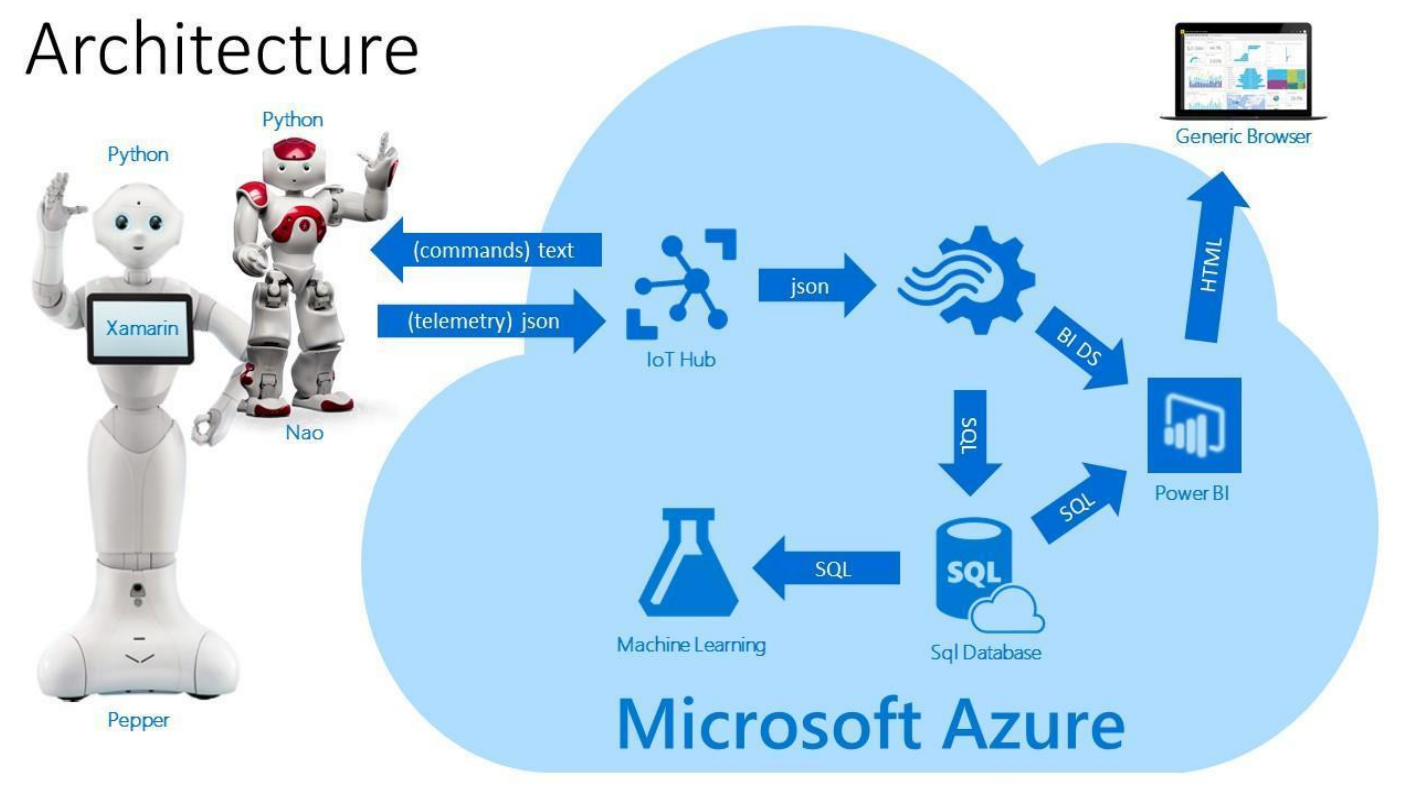

Figure 2: Robot and Cloud Interaction, Avatarion Technology ${ }^{92}$

88 "What is Avatar Kids?," Avatarion, last accessed June 18, 2018, https://www.avatarion.ch/en1/what-we-do/avatar-kids-solution/.

89 "Avatarion," Partners, Softbank Robotics, last accessed August 1, 2018, https://www.softbankrobotics.com/emea/en/avatarion. See also "Robots," Softbank Robotics, last accessed June 18, 2018, https://www.softbankrobotics.com/emea/en/robots. Note that in the website of Avatarion one can buy one of these robots, cfr. https://www.avatarion.ch/en-1/what-we-do/.

90 "Using robots and an loT solution, Avatarion helps sick children stay connected," Saurenmann, R. and Casada, K., Technical Case Studies, Microsoft, last modified April 4, 2017, https://microsoft.github.io/techcasestudies/iot/2017/04/04/avatarion.html.

91 Ibidem. For loT Hub, see also https://azure.microsoft.com/en-gb/services/iot-hub/; for the Stream Analytics see https://azure.microsoft.com/en-gb/services/stream-analytics/; for the SQL Database see https://azure.microsoft.com/en-gb/services/sql-database/; and for the Power $\mathrm{BI}$ see https://powerbi.microsoft.com/en-us/. For the figure see "Using robots and an loT solution, Avatarion helps sick children stay connected," op. cit.

${ }^{92}$ Saurenmann and Casada (2017), supra note 90. 


\begin{tabular}{|l|l|}
\hline \multicolumn{2}{|c|}{ Avatarion Stakeholder Relationships } \\
\hline Role & Legal/Natural Person \\
\hline Users & Patients and their relatives / friends \\
\hline Customers & Hospitals \\
\hline Robot Service Provider & Avatarion \\
\hline Cloud Service Provider & Microsoft \\
\hline Hardware Manufacturer & Softbank Robotics \\
\hline
\end{tabular}

Table 1: Relationship Summary of the Avatarion example

A second example relates to iRobot's "Roomba" internet-connected robotic vacuum cleaner, launched in September 2015. iRobot relied initially on a third-party cloud service to offer customers the ability to control their robotic vacuum cleaner from their smartphones. However, as the number of connected Roombas grew rapidly, iRobot "couldn't achieve the scale and extensibility we needed with the turnkey solution we were using". ${ }^{93}$ Amazon Web Services (AWS) Cloud enabled iRobot to use a serverless architecture. ${ }^{94}$ iRobot uses Amazon Kinesis to process and analyse real-time data; AWS Lambda to execute code in response to triggers; and AWS IoT Core to connect devices easily to the cloud.

\begin{tabular}{|l|l|}
\hline \multicolumn{2}{|c|}{ Roomba Stakeholder Relationships } \\
\hline Role & Legal/Natural Person \\
\hline Users & Consumer or organisation using Roomba \\
\hline Robot Service Provider and Hardware Manufacturer & iRobot \\
\hline Cloud Service Provider & Amazon \\
\hline
\end{tabular}

Table 2: Relationship Summary of the Roomba example

\section{What is regulated in cloud robotics?}

\subsection{The fragmented and uncertain regulatory framework for cloud robotics}

We are not aware of any regulatory framework, mandatory or voluntary, that has been developed specifically for cloud robotics. However, as with other emerging technologies,

\footnotetext{
93 "iRobot Ready to Unlock the Next Generation of Smart Homes Using the AWS Cloud," AWS, Amazon, last accessed June 18, 2018, https://aws.amazon.com/solutions/case-studies/irobot/.

94 Serverless computing allows customers to create practically any type of application or backend service without the need to worry about anything required to run and scale the application. See https://aws.amazon.com/serverless/.
} 
many existing laws and regulatory requirements apply to cloud robotics and a partial regulatory framework can be pieced together based on existing measures. ${ }^{95}$

Robots may be regulated as products under Directive 2001/95/EC on general product safety and Directive 85/374/EEC on liability for defective products. Depending on their use, robots may also be subject to specific legislation. For example, national laws based on the Machinery Directive 2006/42/EC may regulate industrial robots; Regulation 2017/745 on medical devices may apply to robots with an intended medical purposes; and Directive 2009/48/EC on the safety on toys may be relevant for robot toys designed for or intended to be used by children under 14 years old. The low voltage Directive 2014/35/EU might apply to some service robots, e.g. robotic vacuum cleaners; and the electromagnetic compatibility Directive 2014/30/EU and the radio equipment Directive 2014/53/EU may apply to robots incorporating a global positioning system (GPS). If robots have capabilities for processing personal data, the controllers and processors of such data may be regulated by the GDPR and other applicable legislation. In addition, robots may be regulated by more general laws, including tort law.

These examples illustrate the patchwork nature of the current regulation of cloud robotics. As mentioned above, the EC recently issued an open European consultation acknowledging that areas such as autonomous cars, service robots or co-bots are not covered by current legislation. Moreover, the "complex and sophisticated interdependencies both within products (based on hardware and software) and across interconnected devices" challenge the legal certainty regarding the applicable legal framework. ${ }^{96}$ For instance, EU product liability rules differentiate between products and services. However, cloud robotics comprises a "product interconnected with services, (...) an inseparable mixture of hardware, software and service," $"$ that challenges the concept of product. This may also have an impact on the notion of defect, as a defect may be difficult to define and detect in complex and intangible products. ${ }^{98}$ This suggests that the applicability of product liability laws might not be straightforward in the context of physically embodied robots comprising complex software systems and cloud services.

Several EU institutions have highlighted the need to increase legal certainty in the areas of CPS and robotics. In 2015, the EC, as part of its Digital Single Market Strategy, pointed out that concerns about security, and compliance with fundamental rights, were preventing businesses and consumers from full adoption of cloud services for storing and processing data in the context of IoT. ${ }^{99}$ The following year, the EC stated that the increase in humanmachine interaction involving autonomous systems may challenge safety and liability rules,

95 "EU product safety framework for advanced robots \& autonomous systems," Stoica, F., DG Grow, http://ec.europa.eu/information society/newsroom/image/document/2017-30/felicia stoica -

the existing eu safety framework with regard to autonomous systems and advanced robots iot-systems 6210B836-9707-D592-D33613EE1C6F086A 46145.pdf.

96 "Building a European Data Economy," $\operatorname{COM}(2017) 9$ final, last modified January 10, 2017, p. 4, https://eur-lex.europa.eu/legal-content/EN/TXT/PDF/?uri=CELEX:52017DC0009\&from=EN.

${ }^{97}$ La Diega, G.N., and Walden, I.. "Contracting for the 'Internet of Things': Looking into the Nest." European Journal of Law and Technology 7, no. 2 (2016).

98 The evaluation of the Directive 85/374/EC op. cit. actually mentions in p. 87 that "the notion of defect might be misleading when dealing with robotics."

99 "A Digital Single Market Strategy for Europe," COM(2015) 192 final, last modified, May 6, 2015, p. 14, https://eur-lex.europa.eu/legal-content/EN/TXT/PDF/?uri=CELEX:52015DC0192\&from=EN. 
and have wider implications that should be addressed. ${ }^{100}$ In 2017, the EP suggested that the development of autonomous cognitive features in robotics may make the current rules on strict liability insufficient. ${ }^{101}$

The lack of legal and regulatory clarity may have a negative impact on the roll-out and uptake of robots and associated data-driven products and services. The EC has proposed various actions to increase legal certainty including the revision of the Directive 85/374/EEC on liability for defective products, the exploration of risk-based liability regimes, and a review of the Machinery Directive 2006/42/EC. ${ }^{102}$ To date, the results of these actions are inconclusive. In particular:

1. The analysis of Directive $85 / 374 /$ EEC on liability for defective products showed that although the Directive remained relevant in terms of its initial objectives, it was ineffective or irrelevant in relation to new technological developments such as cloud technologies and robots. ${ }^{103}$ The report found that the core concepts product, producer, and defect (Arts. 2-3 and 6) are problematic when applied to products with interconnected services, because the intangible elements blur the line between product and service categories. ${ }^{104}$ Further guidance on this directive is planned for mid-2019. ${ }^{105}$

2. The EP and the EC are undecided on how to frame liability rules for robots in terms of strict liability or risk-based liability. Whereas strict liability would only require proof of the damage and a causal link between the functioning of the robot and the damage, a risk-based approach would focus on which person or entity is best placed to manage particular risks and address negative impacts. ${ }^{106}$ Both institutions agree on the importance of insurance schemes, but are unclear as to the types of robots and harms that such schemes should cover.

100 The exact text reads "Autonomously acting systems such as self-driving cars or drones pose a challenge to current safety and liability rules where a legal person is ultimately responsible. Legal implications of the roll-out of loT are wider than the allocation of liability as recognised in the DSM strategy and also need to be addressed." See also "Digitising European Industry Reaping the full benefits of a Digital Single Market," $\operatorname{COM(2016)} 180$ final, last modified April 19, 2016, p. 13, https://eur-lex.europa.eu/legal-content/EN/TXT/PDF/?uri=CELEX:52016DC0180\&from=EN.

101 The European Parliament Resolution (2017), supra note 36, defines autonomy as the ability to take decisions and implement them in the outside world, independently of external control or influence.

102 "What is a Robot under EU Law?" García Molyneux, C. and Oyarzabal, C. Global Policy Watch, Key Public Policy Developments Around the World, last modified August 4, 2017, https://www.globalpolicywatch.com/2017/08/what-is-a-robot-under-eu-law/.

103 The document also refers to artificial intelligence and 3D printers, see Evaluation of Council Directive 85/374/EEC on the approximation of laws, regulations and administrative provisions of the Member States concerning liability for defective products, last modified May 7, 2018, p. 89, https://publications.europa.eu/en/publication-detail//publication/d4e3e1f5-526c-11e8-be1d01aa75ed71a1/language-en.

${ }^{104}$ Evaluation of the Directive 85/374/EEC (2017), supra note 103.

105 "Commission Actions," Liability of Defective Products, last accessed July 5, 2018, https://ec.europa.eu/growth/single-market/goods/free-movement-sectors/liability-defectiveproducts en.

${ }^{106}$ See European Parliament Resolution (2017), supra note 36. 
3. The analysis of the Machinery Directive noted that robots outside the industrial environment are excluded from the current harmonized standards, as are collaborative robotic systems and risk assessment processes. ${ }^{107}$ The report, however, failed to address what measures and actions could overcome the issues it identified in relation to CPSs.

In sum, the current legal framework for cloud robotics is characterized by a lack of specific regulation, uncertainties with regard to the application of the current framework to new technologies, and a lack of clarity regarding basic concepts and definitions.

It is important that policymakers preserve a balance between regulation and innovation, especially when technology is at its infancy and impacts are uncertain but users already require protection. In the early stages of technology development hard law regulation may make little sense as impacts are unclear and the risk of overregulation is high; whereas at a more mature stage of technology development, reliance on, for example, non-binding guidelines alone may amount to under-regulation. ${ }^{108}$

\subsection{A balance is needed between private standard-setting and public law- making in regulating cloud robotics}

\subsubsection{Why standards are good for cloud computing and robotics}

States are ill-equipped to govern cloud computing on an international basis because, as Reed has argued, "no state has a stronger claim than any other to regulate the entirety of a cross-border computing activity." 109 Self-regulatory governance can overcome this crossborder legitimacy defect, and, in the case of cloud computing, it can promote an open and competitive market, allow interoperability and application portability between cloud providers, and enable trust among cloud customers. ${ }^{110}$

Moreover, specific technological advances in the field of cloud robotics may challenge the application of established legal and regulatory mechanisms. For example, as discussed above, new devices and services may not fit readily into existing categories. Thus, a robot using cloud services might not just be a product in the narrow sense but rather a product with interconnected services. This, and the fact that many laws establish general principles,

107 "Evaluation of the Machinery Directive," European Commission, last modified May 13, 2016, p. 190 ,

https://ec.europa.eu/docsroom/documents/25661/attachments/1/translations/en/renditions/native; See also Simmonds, Brown, and Rentel (2017), supra note 66.

108 This is often referred to as 'the Collingridge Dilemma'. See Collingridge, D. "The Social Control of Technology," New York: St. Martin's Press, 1980. See also Fosch Villaronga, E. and Heldeweg, M. A., 'Regulation, I Presume?', Said the Robot. Towards an Iterative Regulatory Process for Robot Governance. Computer Law and Security Review (2018): forthcoming.

109 Reed, C. "Cloud governance: the way forward." In: Millard, C. Cloud Computing Law. Oxford University Press, 2013, 363.

110 See discussion by Gleeson and Walden of standards for interoperability (European Telecommunications Standards Institute (ETSI), "Cloud Standards Coordination Final Report" November 2013) and data and application portability (ISO/IEC 17826:2012 (SNIA) Information technology - Cloud Data Management Interface (CDMI)), standards for cloud security and data protection (ISO/IEC 27018:2014 Information technology - Security techniques - Code of practice for protection of personally identifiable information (PII) in public clouds acting as PII processors), and standards concerning cloud metrics and service levels in Gleeson, N., and Walden, I. "'It's a Jungle Out There'?: Cloud Computing, Standards and the Law." In European Journal of Law and Technology, vol 5, No 2, 2014. 
might hinder the understanding of what concrete steps a producer needs to follow to make sure that a particular product is deemed to be safe. ${ }^{111}$

When public policy-makers cannot keep up with technological advances, ${ }^{112}$ private actors may seek to govern behaviours by developing private standards. Such standards may provide a useful mechanism for regulating transnational activities where States cannot reach political agreement through binding international law. ${ }^{113}$ For instance, international automotive and mapping companies in the EU, US and Asia have proposed a standardized interface specification for use in the automotive industry. ${ }^{114}$ Public policymakers sometimes encourage private standards, in order to provide a level of certainty when it comes to product safety and consumer protection. In fact, the more standards address public policy purposes rather than merely internal industry interests, the greater the likelihood of the standard having legal effect. ${ }^{115}$ This debate raises a broader issue for policy makers in terms of what part standards can, and should, play in in promoting the uptake of robots.

The EP has called on the EC to continue harmonizing technical standards for robot technology in order to ensure future competition in the field of robotics. ${ }^{116}$ Standards are good for robotics because they promote confidence in the safety of robots. Industrial standards have focused on ensuring human safety, typically by separating humans from operational robotics and by making the robot task predictable and defined (ISO/TC 199 Safety of Machinery). The humans in contact with industrial robots are normally specialists or trained users. Standards for service robots address human-robot interaction aspects because these robots interact with non-expert users, and in non-defined environments (ISO 13482:2014 Safety Requirements for Personal Care Robots). These standards have stipulated safety requirements relating to various design factors, including robot shape, robot motion, energy supply and storage, and autonomous decisions.

In order to achieve interoperability between different robots, there are standardization activities for map and location information, for common interfaces and platform architecture. ${ }^{117}$ In addition, the Robot Operating System (ROS), provides an open robotics middleware platform designed to manage heterogeneous and complex hardware

\footnotetext{
111 Koops, B.J., and Leenes, R. "Privacy regulation cannot be hardcoded. A critical comment on the 'privacy by design' provision in data-protection law." International Review of Law, Computers \& Technology 28, no. 2 (2014): 159-171. See also Verbruggen who notes that the concept of producer is multi-layered in ICT supply chains. Verbruggen, P., Wolters, P., Hildebrandt, M., Sieburgh, C., and Jansen, C. "Towards Harmonised Duties of Care and Diligence in Cybersecurity." (2016). Cyber Security Council, European Foresight Cyber Security Meeting, May 11, 2016, pp. 78-107.

112 "Laws and Ethics Can't Keep Pace with the Technology," Wadhwa, V., MIT Technology Review, last modified April 15, 2014, https://www.technologyreview.com/s/526401/laws-and-ethics-cant-keeppace-with-technology/.

113 Jurčys, P., Kjaer, P.F., and Yatsunami, R. Regulatory Hybridization in the Transnational Sphere. Martinus Nijhoff Publishers, (2013):171-186.

114 "HERE, automotive companies move forward on car-to-cloud data standard," Here, Retrieved from https://www.here.com/en/company/newsroom/press-releases/2016-29-06.

115 See Gleeson and Walden (2014), supra note 110.

116 See European Parliament Resolution (2017), supra note 36.

117 Kamei, K., Nishio, S., Hagita, N., and Sato, M. "Cloud networked robotics." IEEE Network 26, no. 3 (2012): 28-34.
} 
applications. ROS provides libraries and tools to help software developers create robot applications. ${ }^{118}$

\subsubsection{Factors complicating the development of standards for cloud robotics}

Both public and private forms of regulation have advantages and disadvantages. Public policymaking enhances the capacity for enforcement, establishes consequences for violations and constrains auto-interpretation and opportunistic behaviour. ${ }^{119}$ Standards may provide reassurance to consumers, give legitimacy vis-a-vis external actors, and may provide an optimum degree of order in a given international context. ${ }^{120}$ Nevertheless, standards do not, in themselves, establish consequences for violations, since they do not set legally binding rules. In addition, there is a risk that private actors set standards in a way that protects their private interests, instead of promoting public objectives. Moreover, frequent changes, updates, and non-open access rules may make regulation via standards opaque to outsiders. ${ }^{121}$

The problem with cloud standards is twofold. First, it is not very clear what a cloud standard is. As a result, calls for such standards can lead to a wide variety of outcomes. Second, there are many organizations working on and developing cloud standards in parallel. ${ }^{122}$ Further complexity arises from the fact that cloud standards can be technical, if they specify the content of a protocol; informational, if they set Service Level Agreements; or evaluative, if they establish rules for testing and certification of best-practices. ${ }^{123}$

The problem with available robot standards is also twofold. First, apart from the Machinery Directive, European legislation does not directly reference any robot standard. Second, robot standards tend to be single-impact based. For instance, ISO 13482:2014 merely established physical safety requirements for personal care robots. However, the deployment of robot technologies may also have societal and ethical consequences such as a loss of human contact or reinforcement of existing socio-economic inequalities. Other legal principles and values such as privacy, dignity, data protection, and personal autonomy, are often disregarded in standard setting. ${ }^{124}$

To establish a more holistic approach and fill regulatory gaps, private actors may need to develop standards that cover aspects other than simply safety. However, such efforts are in their infancy. Examples include the British Standard (BS) 8611:2016 "Robots and Robotic Devices. Guide to the ethical design and application of robots and robotic systems" and the

118 See http://wiki.ros.org. See also Quigley, M., Conley, K., Gerkey, B., Faust, J., Foote, T., Leibs, J., Wheeler, R., and Adrew Y. "ROS: an open-source Robot Operating System." In ICRA workshop on open source software, vol. 3, no. 3.2, (2009): 5.

119 Abbott, K.W., and Snidal, D. "Hard and soft law in international governance." International organization 54, no. 3 (2000): 421-456.

120 "ISO/TMB Policy and Principles Statement. Global Relevance of ISO Technical Work and Publications," ISO, last $\quad$ accessed July https://www.iso.org/files/live/sites/isoorg/files/developing standards/docs/en/global relevance.pdf.

121 See Reed (2013), supra note 109.

122 See Gleeson and Walden (2014), supra note 110.

123 lbid.

124 Fosch-Villaronga, E., and Golia, A.Jr. "The Intricate Relationships between Private Standards and Public Policymaking in the Case of Personal Care Robots. Who Cares More?" In: Barattini, P. (ed.) Experiments Comparison and Benchmarking in Social and Emotional Robotics. Taylor and Francis, 2018, forthcoming. 
IEEE Ethically Aligned Design from the IEEE Global Initiative and Standard Association. The first identifies twenty ethical hazards and risks grouped by societal, application, commercial/financial and environmental categories, and provides guidelines to mitigate or reduce risk associated with these categories to an acceptable level. They provide engineers with the tools to conduct an ethical risk assessment. Although created de novo, these guidelines are built on existing safety requirements for industrial, personal care and medical robots. The second initiative aims "to ensure every technologist is educated, trained, and empowered to prioritize ethical considerations in the design and development of autonomous and intelligent systems." ${ }^{125}$ While some researchers have already pointed out that concepts such as privacy cannot be hardcoded, ${ }^{126}$ the standard has an entire section on how to promote the embedding of values into autonomous intelligent systems.

So, to realise the full potential of cloud robotics, common standards are likely to be required. To date, technical standards for cloud computing and for robots have been developed along separate tracks and standards concerning cloud robotics are still to be defined. ${ }^{127}$ In relation to robots deployed in social environments, it may also be important for cloud robotics standards to cover social aspects of the HRI, including multi-robot management, multi-area management (spatial information of different locations), user attribute management (supporting daily activities of various users), and service coordination management (managing information exchange and state of the service execution). ${ }^{128}$ As a result, to realize a comprehensive regulation of cloud robotics, a co-regulation model is likely to be required, combining public policymaking with private standard setting. ${ }^{129}$

\section{What are the responsibilities of the key participants?}

\subsection{Attributing legal responsibility in complex multi-party ecosystems}

The main responsibility for product safety falls on producers, which may include 1) manufacturers that supply products on the market, 2) manufacturers that supply products for own use, 3) importers (in certain cases), and 4) businesses/users that change features of the product in order to customise it. ${ }^{130}$ If a robot is designed to perform a task, and runs proprietary software, then liability may be quite straightforward. As Calo explains, if a Roomba harms someone when vacuuming the floor, then iRobot will probably be held liable

\footnotetext{
125 IEEE Ethically Aligned Design 2016, available at https://ethicsinaction.ieee.org.

126 Koops and Leenes (2014), supra note111.

127 Merle, P., Gourdin,C., and Mitton, N. "Mobile cloud robotics as a service with OCClware." In 2017 IEEE International Congress on Internet of Things (ICIOT) (2017): 50-57.
}

128 Kamei, K., Zanlungo, F., Kanda, T., Horikawa, Y., Miyashita, T., \& Hagita, N. "Cloud networked robotics for social robotic services extending robotic functional service standards to support autonomous mobility system in social environments." In 14th International Conference on Ubiquitous Robots and Ambient Intelligence (URAI) 2 (2017): 897-902.

129 Co-regulation is defined as "consensual arrangements, intentionally agreed upon by state and nonstate actors directly involved in setting and enforcing rules." See Graz, J.C., and Nölke, A. (eds.) Transnational private governance and its limits. Routledge, 2008, 12. See also Marsden, Christopher T. Internet co-regulation: European law, regulatory governance and legitimacy in cyberspace. Cambridge University Press, 2011.

130 Stoica (2017), supra note 95. 
because it has built the hardware and written the software. ${ }^{131}$ If, however, a Roomba is modified or is used for other purposes, then iRobot might seek to avoid liability.

However, in a cloud robotics ecosystem there may be multiple players, and chains of responsibility may be extensive, complex and often opaque (even to the parties). ${ }^{132}$ Robot providers may be dependent on cloud service provider(s) and any sub-providers and it may be difficult to understand faults or errors, determine causality, and attribute responsibility. A cloud robotics research scientist at iRobot has commented that one of the biggest problems in relying on cloud services for robotics is visibility: "you only know what your provider tells you". ${ }^{133}$

Determining which party should be held accountable for a particular harm is particularly challenging for issues that arise from the composition of, and interactions between, components managed by different entities, rather than from a single entity failing to act appropriately. ${ }^{134}$ For example, in the case of damage resulting from a technology failure in a cloud robotics ecosystem, an aggrieved party may sue a robot provider for compensation for a failure to take reasonable steps to avoid foreseeable risks. ${ }^{135}$ However, to establish causation, a claimant may need access both to information held by the cloud provider(s) regarding the specific incident, as well as to more general information about how the cloud robotics ecosystem works. It may be difficult to establish a legal basis to compel the cloud service providers to explain how their technology works or otherwise provide technical transparency. ${ }^{136}$ This illustrates how the complex, multi-party ecosystems of cloud robotics can complicate the process of attributing legal responsibility.

To pre-empt having to deal with such liability and transparency issues after-the-fact, the parties can seek to establish their responsibilities through contracts beforehand. However, most cloud computing services are provided on the basis of standard, non-negotiable terms of service. ${ }^{137}$ Robot providers should consider whether these standard terms of service are appropriate, given the particular risks of real-world, physical effects. Alternatively, they could try to negotiate specific terms, if cloud providers are willing.

131 See "South Korean woman's hair 'eaten' by robot vacuum cleaner as she slept," McCurry, J., The
Guardian, last modified February 9, 2015, https://www.theguardian.com/world/2015/feb/09/south-
korean-womans-hair-eaten-by-robot-vacuum-cleaner-as-she-slept; and "The Need to Be Open: U.S.
Laws Are Killing the Future of Robotics," Calo, R., Mashable U.K., last modified January 1, 2014,
https://mashable.com/2014/01/01/us-law-robotics-future/?europe=true. 132 Millard, C., Hon, W.K., and Singh, J. "Internet of Things Ecosystems: Unpacking Legal Relationships and Liabilities." In 2017 IEEE International Conference on Cloud Engineering (IC2E), (2017): 286-291.

133 "Serverless loT at iRobot," Khoe, B., Cloud Robotics Research Scientist, iRobot, last modified March 30, 2018, https://www.infog.com/presentations/serverless-iot-irobot.

${ }^{134}$ Singh, J., Millard, C., Reed, C., Cobbe, J., and Crowcroft, J. "Accountability in the loT: Systems, Law, and Ways Forward." Computer 51, no. 7 (2018): 54-65.

135 For example, under the law of negligence based on breach of a duty of care. Ibid.

136 Ibid.

137 Millard, C. "Cloud Computing Transactions." In: Millard, C. (ed.) Cloud Computing Law, Oxford University Press, 2013, 37. 


\subsection{Sources of liability in cloud robotics}

Insufficient or poorly curated training data for robot task learning and performance may compromise the correct functioning of a robot, e.g. navigation systems may not work well indoors or in dynamic environments where objects move. ${ }^{138}$ In the case of robots that are designed to function 'autonomously', such errors in data analysis can have direct, and in some cases serious, physical consequences. As Amodei et al. explain: "systems that simply output a recommendation to human users, such as speech systems, typically have relatively limited potential to cause harm. By contrast, systems that exert direct control over the world, such as machines controlling industrial processes, can cause harms in a way that humans cannot necessarily correct or oversee." 139 This complexity may hinder the identification of the origin of a problem, the calculation of its consequences and its subsequent future impacts. This may challenge the regulatory framework in a way not encountered with standalone robots. ${ }^{140}$

As noted already in relation to loT ecosystems, ${ }^{141}$ robots are constructed systems with different components, including hardware, software, and cloud services that may be provided by different companies. Buddy is an open source and "open-hardware-botic" robot - meaning anyone can build accessories for the physical robot embodiment. ${ }^{142}$ In this case, if a robot causes unintended harmful behaviour, ${ }^{143}$ it may be necessary to examine the terms of the relevant contracts between the different parties to determine liability.

In the specific context of cloud robotics, there may be a possibility to offload certain heavy computational or data-intensive processes to the cloud. If, however, the robot were to lose functionality because of reduced connectivity, this might have safety or security implications. A risk assessment may indicate that certain critical functions must operate onboard the robot and independent of any connectivity, or even lead to the conclusion that robots cannot perform certain critical tasks due to risks of inappropriate function or inoperability that might result from connection loss.

138 Zamora-Gómez, E. "Map-building and planning for autonomous navigation of a mobile robot." Doctoral dissertation, Center for Research and Advanced Studies of the National Polytechnic Institute, Mexico, 2015.

139 Amodei, D., Olah, C., Steinhardt, J., Christiano, P., Schulman, J., and Mané, D. "Concrete problems in Al safety." arXiv preprint arXiv:1606.06565 (2016).

140 Weng, Y.H., and Zhao, S.T.H. "The legal challenges of networked robotics: From the safety intelligence perspective." In International Workshop on Al Approaches to the Complexity of Legal Systems, Springer, Berlin, Heidelberg, (2011): 61-72.

141 E.g., La Diega and Walden (2016), supra note 97.

142 As mentioned by the company: "We made the strategic choice to open our robot architecture and use Unity3D IDE as a foundation, so anyone interested in developing applications for robots can get started right away. Today, all of the major components of our robot are open source (...) In addition, our use of OpenCV with its extensive algorithms and which is also supported by a large global community, gives BUDDY developers unparalleled versatility. Last but not least, BUDDY is an "openhardware-botic". BUDDY's mechanics are open so that developers can build accessories. See "Our technical choices," BlueFrog, last accessed July 10, 2018, http://www.bluefrogrobotics.com/en/buddy/.

143 It is very rare to find research that causes intended harmful behaviour unless it is to show the vulnerabilities of the systems. See Pistono, F., and Yampolskiy, R.V. "Unethical research: How to create a malevolent artificial intelligence." arXiv preprint arXiv:1605.02817 (2016). 
In the context of IoT, the EC has noted some concerns relating to liability for service failures, user rights when a provider unilaterally upgrades a system, ownership of data created in cloud applications, and how disputes will be resolved. ${ }^{144}$ These issues may also be relevant in relation to sources of liability for cloud robotics.

For example, an unintended harmful behaviour may occur when, despite having a welldefined function, a robot behaves in a way that differs from the designer's intent. This has led many researchers to support the idea that the there is a responsibility gap. The concern is that, if a robot learns as it operates, and the robot itself can, in the course of its operation, change the rules by which it acts, then there is no reason why humans should be held responsible for the autonomous behaviours of such a robot. ${ }^{145}$ The EP was persuaded by this analysis and has called on the EC to create a specific legal status for robots - in the form of electronic persons - and to hold them responsible when causing damage. ${ }^{146}$ This has divided expert opinion between those who support the idea of robot personality, ${ }^{147}$ and many others who are very concerned about it. ${ }^{148}$

The fact that the robot behaves in a different way to the designer's intention, should not necessarily exempt the designer from responsibility. Robots using cloud services operate as a part of a complex system comprising various components that may entail multiple processes over which different persons, natural or legal, exercise control and, therefore, might be held responsible. ${ }^{149}$ For instance, a robot may behave in a certain way because the designer has failed to take into account certain environmental variables, because of the particular evaluation method used, because of decisions about cost-savings, because of bad

\footnotetext{
144 Brussels, 27.9.2012 COM (2012) 529 Final Communication from the Commission to the European Parliament, the Council, the European Economic and Social Committee and the Committee of the Regions. See also Millard, Kuan Hon, and Singh (2017), supra note 132.
}

145 Matthias, A. "The responsibility gap: Ascribing responsibility for the actions of learning automata." Ethics and information technology 6, no. 3 (2004): 175-183. See also Hellström, T. "On the moral responsibility of military robots." Ethics and information technology 15, no. 2 (2013): 99-107.

146 The exact text reads: "59. Calls on the Commission (...) f) creating a specific legal status for robots in the long run, so that at least the most sophisticated autonomous robots could be established as having the status of electronic persons responsible for making good any damage they may cause, and possibly applying electronic personality to cases where robots make autonomous decisions or otherwise interact with third parties independently." See European Parliament Resolution (2017), supra note 36.

147 Evaluation of the Directive 85/374/EEC (2017), supra note 103.

148 See the open letter that a lot of policy and robotics experts have written to the Commission to express their concerns: http://www.robotics-openletter.eu/. The European Economic and Social Committee has also stated that it is "opposed to any form of legal status for robots or Al (systems), as this entails an unacceptable risk of moral hazard. Liability law is based on a preventive, behaviourcorrecting function, which may disappear as soon as the maker no longer bears the liability risk since this is transferred to the robot (or the Al system). There is also a risk of inappropriate use and abuse of this kind of legal status." See "Artificial Intelligence," Muller, C., EESC, last modified May 31, 2017, https://www.eesc.europa.eu/en/our-work/opinions-information-reports/opinions/artificial-intelligence. In a similar way, UNESCO and COMEST (World Commission on the Ethics of Specific Knowledge and Technology) commented 'However, it is highly counterintuitive to call them 'persons' as long as they do not possess some additional qualities typically associated with human persons, such as freedom of will, intentionality, self-consciousness, moral agency or a sense of personal identity." See "Report of Comest on Robotics Ethics," UNESCO and COMEST, last modified September 14, 2017, http://unesdoc.unesco.org/images/0025/002539/253952E.pdf.

149 Singh, J., Walden, I., Crowcroft, J. and Bacon, J. (2016) Responsibility \& Machine Learning: Part of a Process. Available at SSRN: https://ssrn.com/abstract=2860048. 
extrapolations from limited samples, or because insufficient training data have been used (with an adverse impact on the learning model of the robot). ${ }^{150}$ Technological complexity should not, in itself, be a reason for removing liability which might otherwise arise. ${ }^{151}$

\subsection{Addressing liability in cloud robotics}

The creation of multidisciplinary testing zones could help in the identification and assessment of systemic or compound risks concerning cloud robotics. ${ }^{152}$ There are already some test beds for robot technology, with a focus on safety and other assessments that can be fed into the design of robots. ${ }^{153}$ Although these testing zones are not mainstream, and there is not much evidence of cloud robotics testing, in the future there could be a multidisciplinary hub where the data generated from these testing zones could be used for evidence-based policymaking. ${ }^{154}$

It is unclear how the suggestion to hold robots liable 'personally' would work in practice. Are robots expected to hold assets to cover their liabilities, and if so, what happens if the liabilities exhaust these assets? Will the robot be declared bankrupt? These are difficult policy decisions that will inevitably be subject to industry lobbying. ${ }^{155}$

A more promising solution is the EP's recommendataion that a compulsory insurance scheme be established to solve the complexities associated with allocation of responsibility for damage caused by autonomous robots. Insurance could cover, for instance, the risks arising from hacking a robot. However, there is an ongoing discussion as to whether the owner/purchaser of a robot should be required to buy such insurance cover, and the market for this type of insurance is at an early stage of development. ${ }^{156}$ A central fund to cover losses in cases where insurance cover does not exist is also considered by the EP. ${ }^{157}$ This could be a good option, as it seems most producers have a general insurance contract that covers some risks, including the costs of compensation relating to defective products. ${ }^{158}$

\footnotetext{
150 Amodei et al. (2016), supra note 139.

151 Johnson, D. G. "Technology with no human responsibility?." Journal of Business Ethics 127, no. 4 (2015): 707-715.

152 Fosch-Villaronga, E. "Artificial Intelligence, Healthcare and the Law: Regulating Automation in Personal Care." Routledge, Taylor \& Francis Group, 2019, forthcoming.

153 The European Robotics League from euRobotics has currently six certified test beds to test robot tasks and functionality benchmarks. See https://www.eu-robotics.net/robotics league/erlservice/certified-testbeds/index.html.
}

154 So far only Japan has adopted this methodology. See Weng, Y.H., Sugahara, Y., Hashimoto, K., and Takanishi, A. "Intersection of "Tokku" special zone, robots, and the law: a case study on legal impacts to humanoid robots." International Journal of Social Robotics 7, no. 5 (2015): 841-857. See also Fosch Villaronga and Heldeweg (2018) supra note 108.

155 See Johnson (2015) supra note 151. In a similar line, see Bryson, Joanna J., Mihailis E. Diamantis, and Thomas D. Grant. "Of, for, and by the people: the legal lacuna of synthetic persons." Artificial Intelligence and Law 25, no. 3 (2017): 273-291.

156 Bertolini, Andrea, Pericle Salvini, Teresa Pagliai, Annagiulia Morachioli, Giorgia Acerbi, Filippo Cavallo, Giuseppe Turchetti, and Paolo Dario. "On robots and insurance." International Journal of Social Robotics 8, no. 3 (2016): 381-391.

157 This is similar to the approach suggested by Millard, Kuan Hon, and Singh (2017), supra note 132 , who proposed the creation of a central compensation scheme funded by loT ecosystem players to cover those suffering damage from loT devices.

158 Evaluation of the Directive 85/374/EEC (2017), supra note 103. 
Alternative models of liability could be also considered. New Zealand has, for example, a long-established no-fault compensation scheme that covers the costs of almost all injuries and accidents, including injuries caused by medical procedures regardless of who was at fault. ${ }^{159}$ Another option could be to consider cyber-risk insurance for cloud robotics. Some insurers are already providing robotics coverage under cyber insurance policies, although this market is at an early stage of development. ${ }^{160}$

\section{Data protection considerations}

Data protection considerations concerning cloud services and loT have been covered elsewhere. ${ }^{161}$ Robots using cloud services will also typically be used to process large amounts of data, including personal data, and similar issues concerning data protection are likely to arise. ${ }^{162}$ In this section we will focus on the GDPR and, in particular, difficulties in determining the identities and roles of controllers and processors in a cloud robotics ecosystem, the transparency of the processing with regards to HRI, and the potential impact of the right to data portability.

\subsection{In a cloud robotics ecosystem, it may be difficult to identify the controllers and processors of personal data}

Cloud robotics systems may comprise many different components and processes with multiple parties exercising various types of control. Under Art. 4 of the GDPR, the controller is "the natural or legal person [...] which, alone or jointly with others, determines the purposes and means of the processing of personal data;" and the processor is "a natural or legal person, [...] which processes personal data on behalf of the controller." If in the future, as suggested by the EP, certain types of robot are given "electronic personality," it remains to be seen whether a robot might itself be treated as a data controller or a data processor.

Identifying controllers and processors, and managing their relationships, may already be difficult in cloud service arrangements. ${ }^{163}$ A cloud robotics ecosystem is likely to be even more complex due to the combination of multiple hardware manufacturers, software developers, cloud service providers and sub-providers, and users. This may impede the clear understanding of which parties determine, and to what extent, the purposes and means of processing of personal data. It may be a major challenge to identify and map all relevant

\footnotetext{
159 "What we cover," Accident Compensation Corporation (ACC), Te Kaporeihana Awhina Hunga Whara, last accessed July 10, 2018, https:/www.acc.co.nz/im-injured/injuries-we-cover/what-wecover/?smooth-scroll=content-after-navs.

160 "Rise of the Cobots. Collaborative robots, known as cobots, are rapidly expanding in the workforce due to their versatility. But they bring with them liability concerns." Walsh, J., Risk and Insurance, last modified May 2, 2017, http://riskandinsurance.com/rise-of-the-cobots/. See also Millard, Hon, and Singh (2017), supra note 132.

161 Millard, C. ed. Cloud Computing Law, Part III. Oxford: Oxford University Press, 2013; see also La Diega and Walden (2016), supra note 97.

162 Calo, R. "12 Robots and Privacy." Robot ethics: The ethical and social implications of robotics (2011): 187.

163 See Kamarinou, D.; Millard, C.; and Oldani, I. "Compliance as a Service: A review of GDPRmandated contractual relationships between providers and customers of enterprise cloud services", SSRN, forthcoming, 2018; and also Hon, W.K.; Millard, C., and Walden, I. "Who is Responsible for Personal Data in Clouds?" In: Millard, Christopher. "Cloud Computing Law" Oxford University Press, (2013): 193-219.
} 
interactions and communications involving, for example, robot2robot, wearable2robot, robot2cloud, person2robot, sensors2cloud, sensors2robot.

\subsection{Ensuring transparency in cloud robotics may be challenging}

A detailed analysis of the rights of individuals, and the obligations of controllers and processors, is beyond the scope of this paper. However, cloud robotics raises particular challenges in the context of human-robot interactions, as these may involve complex and often opaque data processing activities. ${ }^{164}$ In particular, in a cloud robotics ecosystem it may not be clear to users that they are interacting with more than a physical robot, and that significant aspects of the robot's functioning involve remote processing of data.

The GDPR requires controllers to provide data subjects with transparent information on the identity and contact details of the data controller(s); the purpose(s) and the legal bases of data processing; the recipients or categories of recipients of personal data (if any); where applicable, the intention to transfer data outside the EU and the adequacy decision or appropriate safeguards applied; the period of time personal data is being stored; and data subjects' rights (Arts. 12-15 GDPR). Further, in the case of automated decision-making that may produce legal effects concerning - or similarly significantly affect - the data subject, including profiling, controllers need to provide meaningful information about the logic involved in such a decision. ${ }^{165}$

There is an on-going debate as to whether there is a right to explanation with regard to automated decision-making under the GDPR, ${ }^{166}$ and "explainable robotic systems" is a popular research topic in technical disciplines. ${ }^{167}$ 'Meaningful information' may be difficult to deliver in practice as machine learning algorithms may be complex, and their learning processes may be dynamic and opaque. In many cases, for instance, merely having access to algorithms and data may not be enough to replicate, predict, and thus explain system behaviour, for example because the algorithmic process may have evolved as new training data have been incorporated. ${ }^{168}$ Indeed, it might not be possible to identify precisely what data a robot is collecting, ignoring, or deleting during a particular processing activity. The existence of multiple cloud service providers may further exacerbate the difficulties in discharging each controller's transparency obligations.

Difficult questions may also arise in relation to the meaningfulness of the explanations provided to particular recipients of such information. For instance, in the context of healthcare robots, many systems are developed to be used by groups that are likely to have

\footnotetext{
164 Weng and Zhao (2011), supra note 140; Hon and Millard (2013), supra note 33.

165 See Recitals 39, 71 and articles $13 \mathrm{f}$ ) and $14 \mathrm{~g}$ ) of the GDPR.

166 Kaminski, M.E., "The Right to Explanation, Explained". U of Colorado Law Legal Studies Research Paper No. 18-24, 2018. Available at SSRN: https://ssrn.com/abstract=3196985; Selbst, Andrew D., and Julia Powles. "Meaningful information and the right to explanation." International Data Privacy Law 7, no. 4 (2017): 233-242; Wachter, S. and Mittelstadt, B. and Russell, C. "Counterfactual Explanations Without Opening the Black Box: Automated Decisions and the GDPR." Harvard Journal of Law \& Technology, 31 (2), 2018. Available at SSRN: https://ssrn.com/abstract=3063289, Kamarinou, D., Millard, C., and Singh, J. "Machine Learning with Personal Data." In: Leenes, R., Van Brakel, R., Gutwirth, S., and De Hert, P. Eds. "Data Protection and Privacy: The Age of Intelligent Machines." Bloomsbury Publishing, 2017, 89-112.

167 See https://explainableroboticsystems.wordpress.com/.

168 Kroll, J. A., Barocas, S., Felten, E.W., Reidenberg, J.R., Robinson, D.G., and Yu, H. "Accountable algorithms." U. Pa. L. Rev. 165 (2016): 633.
} 
less capacity than average adults. ${ }^{169}$ As far as the EP is concerned, "it should always be possible to supply the rationale behind any decision taken with the aid of Al that can have a substantive impact on one or more persons' lives; (...) it must always be possible to reduce the Al system's computations to a form comprehensible by humans; (...)". ${ }^{170}$ Moreover, the EP recommends that Licenses for designers should require the development of "tracing tools at the robot's design stage. These tools will facilitate accounting and explanation of robotic behaviour, even if limited, at the various levels intended for experts, operators and users."171

The fulfilment of transparency requirements may also raise consistency issues, as individual units of the same type of robotic or Al system may end up operating in significantly different ways, depending on their individual learning histories. Indeed, in order to establish relationships and lasting attachments between humans and artificial social agents, some robots may simulate personality by exhibiting unique, imperfect, behaviours based on various types of data, collected from various types of sensors, and via cloud computing services. ${ }^{172}$

\subsection{It is unclear how data portability will work in cloud robotics}

The application of data protection principles to robots needs to acknowledge their constitution as cyber-physical systems: they have tangible and non-tangible parts. This greatly affects the appropriate translation of general principles of regulations, including data protection, to these systems.

GDPR Article 20 gives data subjects the right to have returned to them the personal data that they have provided to a data controller in a "structured, commonly used and machinereadable format". The article also gives users the right to "transmit those data to another controller without hindrance from the controller to which the personal data have been provided," and they may require the first controller to make that transfer directly to the second, "where technically feasible". This new right is potentially radical but there is considerable debate as to how it will be applied in practice. ${ }^{173}$ Uncertainties include the basic scope of the right, including whether it only covers information provided directly by a data subject, or whether it might also encompass, for example, passive data collection via sensors such as those in a robot. The transfer of data may also be problematic because different specific robot embodiments might prevent users from making effective use of such data.

\footnotetext{
169 Fosch-Villaronga, E., Felzmann, H., Ramos-Montero, M., and Mahler, T. "Cloud services for robotic nurses? Assessing legal and ethical issues in the use of cloud services for healthcare robots." In IROS 2018 Proceedings, IEEE Xplore Digital Library, 1-5 Oct 2018, Madrid, forthcoming.

170 See European Parliament Resolution (2017), supra note 36.

171 lbid.

172 See Google Patent US 8996429B1 Methods and systems for robot personality development.

173 See De Hert, P., Papakonstantinou, V., Malgieri, G., Beslay, L., and Sanchez, I. "The right to data portability in the GDPR: Towards user-centric interoperability of digital services." Computer Law \& Security Review 34, no. 2 (2018): 193-203.
} 


\section{Concluding remarks}

The growing interdependence between robots and cloud services raises a number of legal and regulatory challenges, including application of data protection rules, adaptation of safety regulations, and evolution of models for attributing responsibility and liability. Potential risks associated with cloud robotics, such as missing or disrupted connectivity and the proliferation of attack surfaces, merit increased attention from technologists, legislators, regulators, and the general public.

Many existing laws and regulatory requirements already apply to cloud robotics, as to any other emerging technology. However, the dual cyber-physical nature of cloud robotics, the complexity of delivery ecosystems, and the number of actors with potential obligations and rights, may drive the development of more integrated governance models.

Some of these challenges relate to the attribution of responsibility. It has been suggested that the concept of legal personality should be extended to robots, mainly to provide a mechanism for applying directly to robots various obligations that currently apply only to individuals and legal persons such as companies. We are not persuaded by such arguments, partly due to practical difficulties such as achieving clarity as to what types of cyber-physical systems should be covered, but more generally because we believe that existing models such as collective insurance may provide a more appropriate basis for managing liability in such contexts.

Applying the provisions of the GDPR to the participants in a cloud robotics ecosystem may be challenging. For instance, identifying data controllers and processors may be difficult in environments where there are multiple service providers. Moreover, a user interacting with a robot might not be aware of the fact that some aspects of the functioning of the robot might be happening elsewhere.

Our conclusion is that any future regulatory initiatives addressing cloud robotics should take into account the complex and dynamic inter-dependence of the tangible and virtual elements of such systems, including possible risk transfers between physical and cyber elements. Care should also be taken to avoid hasty and cumbersome interventions that might be a chilling factor at a time when the potential benefits of cloud robotics are just starting to emerge.

\section{Appendix: glossary of terms used in this paper}

The following chart provides the reader with some basic definitions concerning cloud robotics. These are meant to be working definitions for the purpose of this paper and to synthesize and simplify the wide-ranging discussion on "what is a robot?":

\begin{tabular}{|l|l|}
\hline \multicolumn{2}{|c|}{ Glossary } \\
\hline $\begin{array}{l}\text { Cloud / Cloud } \\
\text { Computing }\end{array}$ & $\begin{array}{l}\text { Model for enabling ubiquitous, convenient, on-demand network access to a } \\
\text { shared pool of configurable computing resources that can be rapidly provisioned } \\
\text { and released with minimal management effort or service provider interaction. }{ }^{174}\end{array}$ \\
\hline Cloud Robotics & $\begin{array}{l}\text { Cloud services providing computation, data and / or storage to support the } \\
\text { operation of a robot. }\end{array}$ \\
\hline
\end{tabular}

174 NIST (2011), supra note 70. 


\begin{tabular}{|c|c|}
\hline $\begin{array}{l}\text { Cyber-physical } \\
\text { system (CPS) }\end{array}$ & $\begin{array}{l}\text { System that integrates computational and physical capabilities, network and } \\
\text { communication processes to interact with its surroundings. }{ }^{175}\end{array}$ \\
\hline $\begin{array}{l}\text { Healthcare } \\
\text { Robot }\end{array}$ & $\begin{array}{l}\text { Systems able to perform coordinated actions on the basis of processing of } \\
\text { information acquired through sensor technology, with the aim to support the } \\
\text { functioning of impaired individuals, medical interventions, care and rehabilitation } \\
\text { of patients and also to support individuals in prevention programs. }{ }^{176}\end{array}$ \\
\hline Industrial Robot & $\begin{array}{l}\text { An automatically controlled, reprogrammable, multipurpose manipulator } \\
\text { programmable in three or more axes, which can be either fixed in place or mobile } \\
\text { for use in industrial automation applications. }{ }^{177}\end{array}$ \\
\hline Robot & $\begin{array}{l}\text { Movable machine that performs tasks either automatically or with a degree of } \\
\text { autonomy. }\end{array}$ \\
\hline $\begin{array}{l}\text { Robot as a } \\
\text { Service (RaaS) }\end{array}$ & $\begin{array}{l}\text { Business model where robotic systems are rented for a period of time, normally } \\
\text { with technical support, real-time monitoring and other services such as security, } \\
\text { policy compliance and hardware failures. }{ }^{178}\end{array}$ \\
\hline $\begin{array}{l}\text { Robotic System } \\
\text { / Ecosystem }\end{array}$ & $\begin{array}{l}\text { Complex network of interacting systems comprising the robot, embedded } \\
\text { sensors, cloud services, ambient intelligent systems, and any device or sensor } \\
\text { supporting robot task performance. }\end{array}$ \\
\hline Service Robot & $\begin{array}{l}\text { Robot that performs useful tasks for humans or equipment excluding industrial } \\
\text { automation application. }\end{array}$ \\
\hline Social Robot & Robot that interacts with humans socially. \\
\hline Soft bot & $\begin{array}{l}\text { (1) Robot without a physical embodiment; } \\
\text { (2) Robot with an embodiment constructed with soft materials and deformable } \\
\text { structures. }{ }^{179}\end{array}$ \\
\hline Wearable Robot & $\begin{array}{l}\text { Body-worn robot that can help the user to perform an intended task, e.g. a worn } \\
\text { exoskeleton that helps a user to stand or walk. }\end{array}$ \\
\hline
\end{tabular}

175 Radhakisan and Gill (2011), supra note 1.

176 The original definition from the European Foresight Monitoring Network (2008) Roadmap Robotics for Healthcare for the definition of healthcare robot (available at http://www.foresight-platform.eu/wpcontent/uploads/2011/02/EFMN-Brief-No.-157 Robotics-for-Healthcare.pdf) also included "coordinated mechatronic actions (force or movement exertions) on the basis of processing of information." We have left this out because we do not believe that it is necessary for healthcare robots. For example, robots that interact socially with humans, eg. as robot counsellors, do not perform such mechatronic actions.

177 ISO 8373:2012 Robots and Robotic Devices - Vocabulary for industrial/service robots.

178 Violino (2017), supra note 12.

179 This is a growing area of research, see "The first autonomous, entirely soft robot," Leah Burrows, SEAS Communications, Hansjörg Wyss Institute for Biologically Inspired Engineering at Harvard University, last modified, August 24, 2016, https://wyss.harvard.edu/the-first-autonomous-entirely-softrobot/. 